\title{
Structural and mechanistic basis of reiterative transcription initiation
}

Yu Liu ${ }^{1,2}$, Jared T. Winkelman ${ }^{1,2,3}$, Libing $\mathrm{Yu}^{1,2}$, Chirangini Pukhrambam ${ }^{2,3}$, Emre Firlar $^{4}$, Jason T Kaelber ${ }^{4}$, Yu Zhang 5 , Bryce E. Nickels ${ }^{2,3, *}$, and Richard H. Ebright ${ }^{1,2, *}$

${ }^{1}$ Department of Chemistry and Chemical Biology, Rutgers University, Piscataway, NJ 08854, USA.

${ }^{2}$ Waksman Institute of Microbiology, Rutgers University, Piscataway, NJ 08854, USA.

${ }^{3}$ Department of Genetics, Rutgers University, Piscataway, NJ 08854, USA.

${ }^{4}$ Rutgers CryoEM \& Nanoimaging Facility, Institute for Quantitative Biomedicine, Rutgers University, Piscataway, NJ 08854, USA.

${ }^{5}$ Key Laboratory of Synthetic Biology, CAS Center for Excellence in Molecular Plant Sciences, Institute of Plant Physiology and Ecology, Chinese Academy of Sciences; Shanghai 200032, China

* Corresponding authors

Keywords:

RNA polymerase

transcription

reiterative transcription initiation

transcriptional slippage

DNA scrunching

RNA slipping

x-ray crystallography

cryo electron microscopy

protein-DNA photocrosslinking

single-molecule DNA nanomanipulation 


\begin{abstract}
Reiterative transcription initiation, observed at promoters that contain homopolymeric sequences at the transcription start site, generates RNA products having 5' sequences non-complementary to the DNA template. Here, using crystallography and cryo-EM to define structures, protein-DNA-photocrosslinking to map positions of RNAP leading and trailing edges relative to DNA, and single-molecule DNA nanomanipulation to assess RNAP-dependent DNA unwinding, we show that RNA extension in reiterative transcription initiation: (1) occurs without DNA scrunching, (2) involves a short, 2-3 bp RNA-DNA hybrid, and (3) generates RNA that exits RNAP through the portal by which scrunched nontemplate-strand DNA exits RNAP in standard transcription initiation. The results establish that, whereas RNA extension in standard transcription initiation proceeds through a scrunching mechanism, RNA extension in reiterative transcription initiation proceeds through a slippage mechanism, with slipping of RNA relative to DNA within a short RNA-DNA hybrid, and with extrusion of RNA from RNAP through an alternative RNA exit.
\end{abstract}




\section{Introduction}

In standard transcription initiation, RNA polymerase (RNAP) holoenzyme binds to promoter DNA, unwinds $\sim 13$ base pairs (bp) of promoter DNA to form an RNAP-promoter open complex (RPo) containing a single-stranded "transcription bubble," selects a transcription start site, and synthesizes the first 10 nucleotides of the RNA product as an RNAP-promoter initial transcribing complex (RPitc) (Chen et al., 2021; Mazumder and Kapanidis, 2019; Ruff et al., 2015; Winkelman et al., 2021). Standard transcription initiation proceeds through a "DNA scrunching" mechanism, in which RNAP unwinds additional DNA, pulls the additional unwound DNA past its active center, and accommodates the additional unwound DNA as single-stranded bulges within the transcription bubble (Kapanidis et al., 2006; Margeat et al., 2006; Revyakin et al., 2006; Winkelman et al., 2015). During standard transcription initiation, each step of RNA extension involves: (i) unwinding of 1 bp of DNA downstream of the RNAP active center, expanding the transcription bubble by $1 \mathrm{bp}$; (ii) translocation of DNA and

RNA--together--by 1 bp relative to the RNAP active center by 1 bp; (iii) binding, through base pairing, of a complementary nucleoside triphosphate (NTP) to the DNA template strand in the RNAP active center, and (iv) phosphodiester bond formation, resulting in addition of a nucleotide to the RNA 3' end (Winkelman et al., 2021). Standard transcription initiation yields an RNA product having a sequence fully complementary to the DNA template strand. Furthermore, during standard transcription initiation, the RNA product remains fully base paired to the DNA template strand, as an RNA-DNA "hybrid."

In an alternative pathway of transcription initiation, termed "reiterative transcription initiation," “transcriptional stuttering,” or “pseudo-templated transcription,” an RNAP-promoter reiteratively transcribing complex (RPrtc) synthesizes an RNA product having a 5'-end sequence that contains a variable number, up to tens to hundreds, of nucleotides not complementary to the DNA template (Jacques and Kolakofsky, 1991; Turnbough and Switzer, 2008; Turnbough Jr, 2011). Reiterative transcription initiation, which was first observed six decades ago (Chamberlin and Berg, 1962, 1964), competes with standard transcription initiation, both in vitro and in vivo (Cheng et al., 2001; Guo and Roberts, 1990; Han and Turnbough, 1998; Jensen-MacAllister et al., 2007; Liu et al., 1994; Meng et al., 2004; Qi and 
Turnbough, 1995; Severinov and Goldfarb, 1994; Tu and Turnbough, 1997; Vvedenskaya et al., 2015; Wagner et al., 1990). Reiterative transcription initiation is observed at promoters that contain homopolymeric sequences at, or immediately downstream of, the transcription start site, resulting in low yields of standard, full-length RNA products at such promoters (Jacques and Kolakofsky, 1991;

Turnbough and Switzer, 2008; Turnbough Jr, 2011). The extent of reiterative transcription initiation relative to standard initiation can change in response to changes in nucleoside triphosphate (NTP) concentrations (Turnbough, 2019; Turnbough and Switzer, 2008; Turnbough Jr, 2011). Classic examples of genes regulated through changes in the extent of reiterative transcription initiation relative to standard transcription initiation in response to changes in NTP concentrations are Escherichia coli pyrBI and Bacillus subtilis pyrG (Liu et al., 1994; Meng et al., 2004).

The mechanism of reiterative transcription initiation has not been firmly established. It has been hypothesized that reiterative transcription initiation involves an "RNA slipping" mechanism, in which RNA extension does not involve translocation of DNA relative to the RNAP active center, but, instead, involves translocation of RNA--“slippage"--relative to both DNA and the RNAP active center (Guo and Roberts, 1990; Jacques and Kolakofsky, 1991; Macdonald et al., 1993; Murakami et al., 2017; Severinov and Goldfarb, 1994; Shin et al., 2020; Turnbough and Switzer, 2008; Turnbough Jr, 2011; Vvedenskaya et al., 2015; Wagner et al., 1990). However, direct evidence for RNA slipping has not been presented, and the mechanism by which long reiteratively transcribed RNA products--RNA products tens to hundreds of nucleotides in length--leave the RNAP active center has not been defined.

Crystal structures have been reported of RPrtc (Murakami et al., 2017; Shin et al., 2020). However, in those structures, (i) transcription-bubble nontemplate-strand DNA was extensively disordered (3-8 nt disordered), complicating assessment of nontemplate-strand DNA scrunching; (ii) transcription-bubble template-strand DNA was partly missing and partly disordered ( $5 \mathrm{nt}$ missing; $3 \mathrm{nt}$ disordered), precluding assessment of template-strand DNA scrunching; (iii) the position of the RNA 3'-end relative to the DNA template strand did not permit further reiterative transcription (template-strand homopolymeric sequence not aligned with RNAP active-center addition site), precluding assessment of 
the mechanism of RNA extension; and (iv) only complexes with short RNA products (6-8 nt) were analyzed, precluding assessment of how long reiterative-transcription-generated RNA products exit the RNAP active-center cleft (Murakami et al., 2017; Shin et al., 2020). As a result of these limitations, the previous crystal structures did not enable determination of the roles of DNA scrunching and RNA slipping, the length of the RNA-DNA hybrid, and the RNA exit path in reiterative transcription initiation Here, we report crystal structures of RNAP engaged in standard transcription initiation of short RNA products on a template containing a non-homopolymeric sequence and RNAP engaged in reiterative transcription initiation of short RNA products on templates containing template-strand GGG and CCC homopolymeric sequences. In addition, we report a cryo-EM structure of RNAP engaged in reiterative transcription initiation of long--up to at least 50 nt--RNA products on a template containing a template-strand CCC homopolymeric sequence. The structures reveal that, whereas RNA extension in standard transcription initiation involves DNA scrunching, RNA extension in reiterative transcription initiation does not. The structures further reveal that only two template-strand nucleotides (in a post-translocated state) or three template-strand nucleotides (in a pre-translocated state) are positioned to be able to base pair to the RNA product, resulting in a short RNA-DNA hybrid. The cryo-EM structure of RNAP engaged in reiterative transcription initiation of long RNA products further reveals that reiterative-transcription-generated RNA exits RNAP using the path by which scrunched nontemplate-strand DNA exits RNAP in standard transcription initiation, instead of the path by which RNA exits RNAP in standard transcription initiation. Results of two independent orthogonal approaches, site-specific protein-DNA photocrosslinking and single-molecule DNA nanomanipulation, confirm the observed scrunching patterns. Taken together, our results establish that, whereas RNA extension in standard initiation involves DNA scrunching, RNA extension in reiterative initiation involves RNA slipping, with sliding of the RNA product relative to the DNA template strand within a short RNA-DNA hybrid, and with extrusion of RNA from the RNAP active-center cleft through an alternative RNA exit. 


\section{Results}

Crystal structures of RPrtc, 4 and RPrtc,5: RNA extension through RNA slipping without DNA scrunching

We determined crystal structures of Thermus thermophilus RPrtc in which nontemplate-strand DNA is fully ordered, enabling assessment of DNA scrunching, and in which the template-strand homopolymeric sequence is aligned with the RNAP active-center addition site, enabling assessment of RNA slipping (Figures 1-2). For both the crystal structures of this section and the cryo-EM structure below, we analyzed T. thermophilus RNAP because atoms of this hyperthermophilic bacterial RNAP show lower thermal motions at structure-determination temperatures than atoms of mesophilic bacterial RNAP, enabling determination of structures having high order, higher resolution, and superior map quality (Basu et al., 2014; Feng et al., 2016; Murakami et al., 2002a; Murakami et al., 2002b; Murakami et al., 2017; Shin et al., 2020; Vassylyev et al., 2002; Zhang et al., 1999; Zhang et al., 2012). We obtained a crystal structure of RPrtc containing a 5 nt RNA product by incubation of a nucleic-acid scaffold containing a $\mathrm{G}_{+1} \mathrm{G}_{+2} \mathrm{G}_{+3}$ template-strand homopolymeric sequence, where +1 is the transcription start site, with RNAP and CTP (RPrtc,5 $\left[\mathrm{G}_{+1} \mathrm{G}_{+2} \mathrm{G}_{+3}\right]$; Figures $1 \mathrm{C}$ and S1A; Table S1), and we obtained a crystal structure of RPrtc containing a 4 nt RNA product by incubation of a nucleic-acid scaffold containing a $\mathrm{C}_{+1} \mathrm{C}_{+2} \mathrm{C}_{+3}$ template-strand homopolymeric sequence with RNAP and GTP (RPrtc, $4\left[\mathrm{C}_{+1} \mathrm{C}_{+2} \mathrm{C}_{+3}\right]$; Figures 1D and S1A; Table S1). For reference, we compared these structures to a previously reported crystal structure of T. thermophilus RPo (RPo; Figure 1A, Zhang et al., 2012) and a crystal structure of $T$. thermophilus RPitc containing a 5 nt RNA product by incubation of a nucleic-acid scaffold lacking a template-strand homopolymeric sequence with RNAP, ATP, UTP, and CTP (RPitc,5; Figures 1B and S1A; Table S1).

The crystal structure of RPo shows ordered density for all nucleotides of the transcription-bubble nontemplate strand: $5 \mathrm{nt}$ in the -10 element (promoter element recognized by conserved region 2 of transcription initiation factor $\sigma$; Feklistov et al., 2014), $4 \mathrm{nt}$ in the discriminator element (another promoter element recognized by conserved region 2 of transcription initiation factor $\sigma$; Feklistov et al., 
2014), and $4 \mathrm{nt}$ between the discriminator element and downstream dsDNA; Figure 1A, blue, light blue, and pink; (Zhang et al., 2012).

The crystal structure of RPitc, 5 shows an initially transcribing complex with a 5 nt RNA product and an RNAP active-center post-translocated state (Figure 1B). The RNA product is fully base paired to the DNA template strand as an RNA-DNA hybrid, with the RNA 3' nucleotide and the corresponding DNA template-strand nucleotide located in the RNAP active-center product site ("P site"), and the next DNA template-strand nucleotide in the RNAP active-center addition site ("A site") available for base pairing with an incoming NTP. The positions of the RNA and DNA relative to the RNAP active center indicate that, as compared to in RPo, 4 bp of downstream dsDNA have been unwound, $4 \mathrm{nt}$ of each strand has been translocated relative to the RNAP active center, and the RNA product has translocated $4 \mathrm{nt}$ in lock-step register with template-strand DNA. The crystal structure of RPitc, 5 indicates that the 4 nt of nontemplate-strand DNA translocated relative to the RNAP active center are accommodated through DNA scrunching, with bulging of the nontemplate-strand DNA segment between the discriminator element and downstream dsDNA. Thus, the crystal structure of RPitc, 5 shows ordered density for all transcription-bubble nontemplate-strand nucleotides of the - 10 element and the upstream half of the discriminator element, with the same positions and the same $\sigma$-DNA interactions as in RPo, and shows disorder for $8 \mathrm{nt}$ of nontemplate-strand DNA, corresponding to the downstream half of the discriminator element and DNA immediately downstream of the discriminator element (Figure 1B, cyan boxes). The 8 nt segment of disordered nontemplate-strand DNA in RPitc, 5 has exactly the same endpoints, and spans exactly the same distance, as a $4 \mathrm{nt}$ segment of ordered nontemplate-strand DNA in RPo (Figures 1A-B), indicating that $\sim 4 \mathrm{nt}$ of the $8 \mathrm{nt}$ segment of disordered nontemplate-strand DNA are flipped out and/or bulged out relative to the path of the nontemplate strand in RPo (Figure 1B, right, flipped and/or bulged nucleotides in cyan box). The disorder of the $8 \mathrm{nt}$ segment of disordered nontemplate-strand DNA indicates that the segment adopts an ensemble of distinct conformations (Figure 1B, cyan boxes). We conclude that formation of RPitc, 5 involves $\sim 4$ bp of DNA scrunching. 
The crystal structure of RPrtc, $5\left[\mathrm{G}_{+1} \mathrm{G}_{+2} \mathrm{G}_{+3}\right]$ shows a reiteratively transcribing complex with a 5 nt RNA product and an RNAP active-center post-translocated state (Figure 1C). Only part of the RNA product--the part comprising the 3' nucleotide and the adjacent nucleotide--is base paired to the DNA template strand as a 2 bp RNA-DNA hybrid, with the RNA 3' nucleotide and the corresponding DNA template-strand nucleotide located in the RNAP active-center P site, and the next DNA template-strand nucleotide in the RNAP active-center A site available for base pairing with an incoming NTP. The positions of the RNA and DNA relative to the RNAP active center indicate that, as compared to in RPo, 1 bp of downstream dsDNA has been unwound, 1 nt of each strand of DNA has been translocated relative to the RNAP active center, and the 5' end of the RNA product has been translocated by 4 nt relative to the RNAP active center, translocating $1 \mathrm{nt}$ in register with template-strand DNA and $3 \mathrm{nt}$ out of register with template-strand DNA. The crystal structure of RPrtc, $5\left[\mathrm{G}_{+1} \mathrm{G}_{+2} \mathrm{G}_{+3}\right]$ shows that the $1 \mathrm{nt}$ of nontemplate-strand DNA translocated relative to the RNAP active center is accommodated through DNA scrunching, with unstacking and flipping of $1 \mathrm{nt}$ of nontemplate-strand DNA between the discriminator element and downstream dsDNA (Figure $1 \mathrm{C}$, cyan boxes). The crystal structure of RPrtc, $5\left[\mathrm{G}_{+1} \mathrm{G}_{+2} \mathrm{G}_{+3}\right]$ shows ordered density for all transcription-bubble nontemplate-strand nucleotides, including the scrunched, unstacked, flipped nucleotide: $5 \mathrm{nt}$ in the -10 element, $4 \mathrm{nt}$ in the discriminator element, and 5 nt between the discriminator element and downstream dsDNA (Figure 1C). The crystal structure shows graphically that formation of RPrtc, $5\left[\mathrm{G}_{+_{1}} \mathrm{G}_{+2} \mathrm{G}_{+3}\right]$ involves 1 bp of DNA scrunching and 3 nt of RNA slipping.

The crystal structure of RPrtc, $4\left[\mathrm{C}_{+1} \mathrm{C}_{+2} \mathrm{C}_{+3}\right]$ shows a reiteratively transcribing complex with a $4 \mathrm{nt}$ RNA product and an RNAP active-center post-translocated state, a 2 bp RNA-DNA hybrid, 1 bp of unwinding of downstream dsDNA, 1 nt of translocation of each DNA strand, $1 \mathrm{nt}$ of translocation of the 5' end of the RNA product in register with template-strand DNA, and 2 nt of translocation of the 5' end of the RNA product out of register with template-strand DNA (Figure 1D). The crystal structure shows graphically that formation of RPrtc, $4\left[\mathrm{C}_{+1} \mathrm{C}_{+2} \mathrm{C}_{+3}\right]$ involves 1 bp of DNA scrunching and $2 \mathrm{nt}$ of RNA slipping. 
We infer, based on the structures in Figure 1, that standard transcription initiation to generate a post-translocated state of RPitc, $\mathrm{x}$ involves $\mathrm{x}-1$ bp of DNA scrunching, whereas reiterative transcription initiation to form a post-translocated state of RPrtc,x involves $1 \mathrm{bp}$ of DNA scrunching and x-2 nt of RNA slipping. Expressing these inferences in terms of mechanism, we infer that, in standard transcription initiation, following synthesis of a $2 \mathrm{nt}$ initial RNA product, $1 \mathrm{bp}$ of DNA scrunching occurs for each $1 \mathrm{nt}$ of RNA extension (Revyakin et al., 2006), and we infer that, in contrast, in reiterative transcription initiation, following synthesis of a $2 \mathrm{nt}$ initial RNA product, 1 bp of DNA scrunching occurs to position the 3' end of the initial RNA product in the RNAP active-center P site, and no further DNA scrunching--just RNA slipping--occurs in RNA extension (see Discussion).

\section{Crystal structures of RPrtc, 4 and RPrtc,5: short RNA-DNA hybrid}

In the crystal structure of RPitc,5, all nucleotides of the RNA product are complementary to, and base-paired to, the DNA template strand, yielding a 5 bp RNA-DNA hybrid (Figures 1B and 2A). In contrast, in the crystal structures of RPrtc, $5\left[\mathrm{G}_{+1} \mathrm{G}_{+2} \mathrm{G}_{+3}\right]$ and RPrtc, $4\left[\mathrm{C}_{+1} \mathrm{C}_{+2} \mathrm{C}_{+3}\right]$, only the 2 nt at the 3 ' end of the RNA product are complementary to, and base-paired to, the DNA template strand, yielding a 2 bp RNA-DNA hybrid (Figures 1C-D and 2A). We conclude that, unlike standard transcription initiation, reiterative transcription initiation involves a short RNA-DNA hybrid: a hybrid that is only 2 bp in length in the RNAP active-center post-translocated state of the crystal structures ("post-slipped state"), and that would be only $3 \mathrm{bp}$ in length upon NTP binding and phosphodiester bond formation to yield the RNAP active-center pre-translocated state ("pre-slipped state").

In RPrtc, the conformation and interactions with RNAP of the RNA product--even the part of the RNA product that is not complementary to, and not base paired to, template-strand DNA--are the same as in RPitc (Figure 2B). In contrast, in RPrtc, the conformation and interactions of the part of the DNA template strand that is not complementary to, and not base paired to, RNA differ from those in RPitc (Figure 2B). Inspection of structures of RPrtc and RPitc indicates that RNAP makes numerous interactions with RNA, and few interactions with DNA, in the RNAP hybrid-binding region, accounting 
for our observation that RNA conformation, rather than DNA conformation, is maintained upon loss of RNA-DNA complementarity and base pairing.

In our crystal structures of RPitc and RPrtc, the 5' end of the RNA product is in contact with the “ $\sigma$ finger" (also referred to as $\sigma$ region 3.2), which enters the RNAP active-center cleft, and obstructs the path of the RNA product (Figure 1; see, Basu et al., 2014; Li et al., 2020; Mazumder and Kapanidis, 2019; Mekler et al., 2002; Murakami et al., 2002b; Vassylyev et al., 2002; Winkelman et al., 2021; Zhang et al., 2012). In solution, and in some crystal forms under some conditions, extension of the RNA product beyond a length of $5 \mathrm{nt}$ can drive stepwise displacement of the $\sigma$ finger (Li et al., 2020). In contrast, with the crystal forms and conditions of this work, RNA extension does not drive stepwise displacement of the $\sigma$ finger--presumably due to crystal-lattice constraints on conformational change in $\sigma$--and thus RNA products are limited to a length of $5 \mathrm{nt}$.

\section{Cryo-EM structure of RPrtc, $\geq 1$ 1: RNA extension through RNA slipping without DNA scrunching}

Reiterative transcription initiation can generate RNA products up to at least $50 \mathrm{nt}$ in length

(Figure S1; Turnbough and Switzer, 2008; Turnbough Jr, 2011). Because the volume of the RNAP active center cleft in RPrtc cannot accommodate more than $\sim 10$ nt of RNA, long RNA products generated by reiterative transcription initiation must exit from, and extend outside, the RNAP active-center cleft (Murakami et al., 2017). A key unresolved question is where long RNA products generated in reiterative transcription initiation exit the RNAP active-center cleft. In the crystal structures of this work, as in the crystal structures of Murakami et al., 2017 and Shin et al., 2020, RNA products generated by reiterative transcription initiation were limited in length, because further RNA extension was blocked by the presence of the $\sigma$ finger in the RNAP active-center cleft and by crystal-lattice constraints that prevented displacement of the $\sigma$ finger from the RNAP active-center cleft (Basu et al., 2014; Li et al., 2020), opening of the RNAP clamp (Chakraborty et al., 2012; Duchi et al., 2018; Mazumder et al., 2020), or any other conformational change that could open a path for further extension of RNA and for extrusion 
of RNA from the RNAP active-center cleft. One hypothesis is that, in solution, complete displacement of the $\sigma$ finger from the RNAP active-center cleft channel could allow long RNA products generated in reiterative transcription initiation to exit the RNAP active-center cleft through the RNAP RNA-exit channel, the same exit route used by RNA in standard transcription (Murakami et al., 2017). Another hypothesis is that, in solution, a smaller conformational change in $\sigma$ and/or RNAP could allow long RNA products generated in reiterative transcription initiation to exit the RNAP active-center cleft through a different route (Murakami et al., 2017). Consistent with the first hypothesis, our crystal structures show that the 3' region of RNA products generated in reiterative transcription can follow the same path relative to RNAP as in standard transcription initiation (Figure 2). However, arguing against the first hypothesis, it is unclear how, with only 1 bp of DNA scrunching (Figure 1), the system could acquire the energy needed to drive complete displacement of the $\sigma$ finger from the RNAP hybrid binding site and displacement of the $\sigma$ region-3/region-4 linker from the RNAP RNA-exit channel (free energy that, in standard transcription initiation, is thought to be provided by $\sim 8-10$ bp of DNA scrunching; Kapanidis et al., 2006; Revyakin et al., 2006), and it is unclear how the $\sigma$ region-3/region-4 linker could be completely displaced from the RNAP RNA-exit channel without triggering promoter escape (which, in standard transcription initiation, is thought to be triggered by displacement of the region-3/region-4 linker from the RNAP RNA-exit channel; Li et al., 2020; Mekler et al., 2002; Murakami et al., 2002b; Vassylyev et al., 2002).

To resolve these questions, we performed cryo-EM structure determination, analyzing reiteratively transcribing complexes prepared in solution. We incubated a nucleic-acid scaffold containing a full transcription bubble and a $\mathrm{C}_{+1} \mathrm{C}_{+2} \mathrm{C}_{+3}$ template-strand homopolymeric sequence with RNAP and GTP, we applied samples to glow-discharged graphene-oxide-coated grids (Pantelic et al., 2010; Thomas et al., 2016), flash-froze samples, and performed single particle-reconstruction cryo-EM (RPrtc, $\geq 11$ $\left[\mathrm{C}_{+1} \mathrm{C}_{+2} \mathrm{C}_{+3}\right]$; Figures 3-4, S1A, and S2). This approach avoided the limitation imposed by crystal-lattice constraints (Figures 3-4 vs. Figures 1-2 and Murakami et al., 2017; Shin et al., 2020). In addition, by 
analyzing a nucleic-acid scaffold that contained a full transcription bubble, this approach avoided possible limitations imposed by use of a nucleic-acid scaffold that lacked an upstream duplex (Figures 3-4 vs. Figures 1-2 and Murakami et al., 2017; Shin et al., 2020). Use of glow-discharged graphene-oxide-coated grids was essential in order to obtain a satisfactory distribution of particle orientations on grids (Figure S2D).

The cryo-EM structure of RPrtc, $\geq 11\left[\mathrm{C}_{+1} \mathrm{C}_{+2} \mathrm{C}_{+3}\right]$ has an overall resolution of $3.0 \AA$, with higher local resolution for regions of interest, including the transcription-bubble nontemplate and template DNA strands and the RNA product (Figure S2D-E). Map quality is high, with ordered, traceable density for 7 bp of upstream dsDNA, all nucleotides of the nontemplate and template strands of the transcription bubble, $10 \mathrm{bp}$ of downstream dsDNA, and $11 \mathrm{nt}$ of the RNA product corresponding to the $11 \mathrm{nt}$ segment containing the RNA 3' end (Figures 3-4 and S2E).

The cryo-EM structure of RPrtc, $\geq 11\left[\mathrm{C}_{+1} \mathrm{C}_{+2} \mathrm{C}_{+3}\right]$ shows a reiteratively transcribing complex with a long, $\geq 11 \mathrm{nt}$, RNA product and an RNAP active-center post-translocated state (Figure 3A-B). As observed in our crystal structures of RPrtc with short RNA products (Figure 1C-D), the $2 \mathrm{nt}$ at the 3' end of the RNA product are base paired to the DNA template strand and the next $3 \mathrm{nt}$ of the RNA product are close to, but not Watson-Crick base-paired with, the DNA template strand (Figure 3A-B). The next 6 nt of the RNA product follow a previously unobserved path that diverges from the DNA template strand due to a collision with the $\sigma$ finger, crosses the transcription bubble, crosses the DNA nontemplate strand, and exits the RNAP active-center cleft at a position on the face of RNAP opposite the standard RNA exit (“alternative RNA exit"; Figure 3A-B). Additional nucleotides of the long, tens to hundreds of nucleotides, RNA products generated by reiterative transcription under these conditions (Figure S1A) would be located outside the alternative RNA exit and would extend into bulk solvent; these nucleotides are not observed in the structure, presumably due to segmental disorder (Figure 3A-B), analogous to the segmental disorder previously observed for nucleotides of long RNA products located outside the RNAP standard RNA exit (Yin et al., 2019). The structure contains $\sigma$ and exhibits the same $\sigma$-DNA and 
$\sigma$-RNAP interactions, except for those made by the $\sigma$-finger tip (see below), as in RPo (Figure 3A-B),

indicating that production of long RNAs by reiterative transcription initiation does not involve substantial disruption of $\sigma$-DNA and $\sigma$-RNAP interactions and does not involve promoter escape.

As observed in our crystal structures of RPrtc with short RNA products (Figure 1C-D), the positions of the RNA and DNA relative to the RNAP active center indicate that, as compared to in RPo, 1 bp of downstream dsDNA has been unwound, 1 nt of each strand of DNA has been translocated relative to the RNAP active center, and the 5' end of the RNA product has been translocated by $\geq 11$ nt relative to the RNAP active center, translocating $1 \mathrm{nt}$ in register with template-strand DNA and $\geq 10 \mathrm{nt}$ out of register with template-strand DNA. The cryo-EM structure of RPrtc, $\geq 11\left[\mathrm{C}_{+1} \mathrm{C}_{+2} \mathrm{C}_{+3}\right]$ shows that the $1 \mathrm{nt}$ of nontemplate-strand DNA translocated relative to the RNAP active center is accommodated through 1 bp of DNA scrunching, with unstacking and flipping of nontemplate-strand position +1 (i.e., the position $7 \mathrm{bp}$ downstream of the -10 element) and with changes in conformation of the nucleotides flanking nontemplate-strand position +1 (Figure 3B-C, cyan boxes). The cryo-EM structure of RPrtc, $\geq 11$ $\left[\mathrm{C}_{+1} \mathrm{C}_{+2} \mathrm{C}_{+3}\right]$ further shows that the $1 \mathrm{nt}$ of template-strand DNA translocated relative to the RNAP active center likewise is accommodated through 1 bp of DNA scrunching, with unstacking and flipping of template-strand position -9 (i.e., the third position within the -10 element) and with small changes in conformation of template-strand nucleotides downstream of position -9 (Figure 3B-C, cyan boxes). The cryo-EM structure shows graphically that formation of RPrtc, $\geq 11\left[\mathrm{C}_{+1} \mathrm{C}_{+2} \mathrm{C}_{+3}\right]$ involves 1 bp of DNA scrunching and $\geq 10 \mathrm{nt}$ of RNA slipping.

\section{Cryo-EM structure of RPrtc, $\geq 11$ : short RNA-DNA hybrid}

As observed in our crystal structures of RPrtc with short RNA products (Figure 2A), in the cryo-EM structure of RPrtc, $\geq 11\left[\mathrm{C}_{+1} \mathrm{C}_{+2} \mathrm{C}_{+3}\right]$, only the $2 \mathrm{nt}$ at the 3 ' end of the RNA product are complementary to, and base paired to, the DNA template strand, yielding a 2 bp RNA-DNA hybrid (Figures 3A-B and 4A). The structure thus supports our conclusion that, unlike standard transcription 
initiation, reiterative transcription initiation involves a short RNA-DNA hybrid: a 2 bp hybrid in the post-slipped state, and a 3 bp hybrid in the pre-slipped state.

In our crystal structures of RPrtc with short RNA products, the conformation of the RNA nucleotides at positions P-4, P-3, and P-2 relative to the active-center P site--the RNA nucleotides, not complementary to, and not Watson-Crick base-paired to, template-strand DNA--is the same as in a standard transcription initiation complex, and the conformation of the corresponding part of template-strand DNA is different (Figure 2B). In contrast, in the cryo-EM structure of RPrtc, $\geq 11$ $\left[\mathrm{C}_{+1} \mathrm{C}_{+2} \mathrm{C}_{+3}\right]$, the opposite is true: the conformation of the RNA nucleotides at positions $\mathrm{P}-4, \mathrm{P}-3$, and $\mathrm{P}-2$ relative to the active-center $\mathrm{P}$ site differs from the conformation in standard transcription initiation and elongation complexes, and the conformation of the corresponding part of template-strand DNA is the same as in standard transcription initiation and elongation complexes (Figure 4B). The conformations of the RNA product and the DNA template strand at positions P-4, P-3, and P-2 in RPrtc, $\geq 11\left[\mathrm{C}_{+1} \mathrm{C}_{+2} \mathrm{C}_{+3}\right]$ allow formation of non-Watson-Crick, wobble or wobble-like, H-bonds at positions P-3 and P-2 (Figure 4A). The difference in conformation of RNA and DNA at positions P-4, P-3. and P-2 in our crystal structures of RPrtc with short RNA products and our cryo-EM structure of RPrtc, $\geq 11\left[\mathrm{C}_{+1} \mathrm{C}_{+2} \mathrm{C}_{+3}\right]$ likely is attributable to the absence in the former, and presence in the latter, of additional RNA nucleotides 5' to this RNA segment and additional template-strand DNA nucleotides in the full-transcription-bubble nucleic-acid scaffold (Figures 1C-D and 3B).

\section{Cryo-EM structure of RPrtc, $\geq 11:$ RNA exit through nontemplate-strand scrunching portal}

In the cryo-EM structure of RPrtc, $\geq 11\left[\mathrm{C}_{+1} \mathrm{C}_{+2} \mathrm{C}_{+3}\right]$, the RNA segment 6-11 nt from the RNA 3' end (nucleotides rN6-rN11) follows a path that differs by $\sim 130^{\circ}$ from the path of the RNA product in standard transcription initiation and elongation complexes, and that differs by $\sim 30^{\circ}$ from the paths of the shorter RNA products in the crystal structures of RPrtc in Murakami et al., 2017 and Shin et al., 2020 (Figures 3A-B,D and 4C). This RNA segment, nucleotides rN6-rN11, diverges from the path of the RNA 
product in standard transcription initiation and elongation complexes, due to a collision with the $\sigma$-finger tip, involving nucleotide rN6 (Figure 3B,D and 4C, left). This RNA segment, nucleotides rN6-rN11, then cross the transcription bubble, spanning $\sim 20 \AA$, cross the DNA nontemplate strand, spanning an additional $\sim 10 \AA$, and exit from the RNAP active-center cleft at a position on the face of RNAP opposite the RNA exit used in standard transcription elongation complexes (Figures 3B,D and 4C, center and right).

Three residues of the $\sigma$-finger tip make van der Waals interactions with nucleotide rN6, causing the path of nucleotides rN6-rN11 to diverge, by $\sim 130^{\circ}$, from the path of the RNA product in a standard transcription initiation or elongation complex ( $\sigma$ residues D323, E324, and D326; residues numbered here and below as in T. thermophilus RNAP holoenzyme; Figure 4C, left). Four residues of RNAP $\beta$ subunit and one residue of $\sigma$ make H-bonded or salt-bridged interactions with the sugar-phosphate backbone of nucleotides rN6-rN11 ( $\beta$ residues K188, R189, T419 and R420, and $\sigma$ residue K325; Figure 4C). Two residues of RNAP $\beta$ subunit and one residue of $\sigma$ make single H-bonds with RNA bases of nucleotides rN6-rN11 ( $\beta$ residues N187 and G417, and $\sigma$ residue T77; Figure 4C). The observations that most protein-RNA interactions with nucleotides rN6-rN11 involve the sugar-phosphate backbone, and that interactions with bases involve single H-bonds that, with wobble, could be made with any base, suggest that the RNA-exit pathway observed in this structure may be compatible with any RNA sequence. Residues of RNAP $\beta$ subunit that make protein-RNA interactions with nucleotides rN6-rN11 are residues located immediately $\mathrm{N}$-terminal to $\beta$ conserved region $\beta \mathrm{a} 5$ ( $\beta$ residues $187-189$ ) and residues located in $\beta$ conserved region $\beta \mathrm{a}$ 7, also known as fork-loop 2 ( $\beta$ residues 417-420) (Figure S3, left; $\beta$ conserved regions defined as in Lane and Darst, 2010). All six residues of RNAP $\beta$ subunit that interact with nucleotides rN6-rN11 are invariant or highly conserved across Gram-negative, Gram-positive, and Thermus-Deinococcus-clade bacteria (Figure S3, left). Residues of $\sigma$ that make protein-RNA interactions with nucleotides rN6-rN11 are residues at the N-terminus of $\sigma \mathrm{R} 1.2(\sigma$ residue 77$)$ and residues of the part of $\sigma \mathrm{R} 3.2$ that forms the $\sigma$-finger tip ( $\sigma$ residues 323-326) (Figure S3, right; $\beta$ conserved regions defined 
as in Feklistov et al., 2014). Most, three of five, residues of $\sigma$ that interact with nucleotides rN6-rN11 are invariant or highly conserved across Gram-negative, Gram-positive, and Thermus-Deinococcus-clade bacteria (Figure S3B). The observation that residues of RNAP $\beta$ and $\sigma$ that make protein-RNA interactions with nucleotides rN6-rN11 are highly conserved across bacterial species suggest that the RNA-exit pathway observed in this structure may mediate the production of long RNA products by reiterative transcription initiation across bacterial species.

At the point where nucleotides rN6-rN11 cross the DNA nontemplate strand, direct DNA-RNA interactions occur, involving the stacking of the base of the nucleotide at nontemplate-strand position +2 ( $8 \mathrm{nt}$ downstream of -10 element) on the base of nucleotide rN8 (Figure 3B,D and 4C, center). This DNA-RNA base-stacking interaction is facilitated by the 1 nt of scrunching of the nontemplate strand, which, by unstacking and flipping out the nucleotide at nontemplate-strand position +1 , frees the nucleotide at nontemplate-strand position +2 for DNA-RNA base stacking (Figure 3B,D and 4C, center). The ability of nucleotides rN6-rN11 to cross the DNA nontemplate strand is further facilitated by the $1 \mathrm{nt}$ of scrunching of the nontemplate strand in that the unstacking and flipping of the nucleotide at nontemplate strand position +1 opens space for, and removes a steric barrier to. passage of nucleotides rN8 and rN9 past the DNA nontemplate strand.

Nucleotides rN8-rN10 are accommodated within the same cavity within the RNAP active-center cleft that accommodates scrunched nontemplate-strand DNA in standard transcription initiation (Figure 3A-B,D; Basu et al., 2014; Hasemeyer, 2018; Kapanidis et al., 2006; Winkelman et al., 2015). Nucleotide rN11 exits the RNAP active-center cleft and interacts with bulk solvent. Nucleotide rN11 exits the RNAP active-center cleft through the same opening through which long, $\geq 6-8 \mathrm{nt}$, segments of scrunched nontemplate-strand DNA exit the RNAP active-center cleft (alternative RNA exit in Figure 3A-B; nontemplate-strand scrunching portal in Hasemeyer, 2018; Kapanidis et al., 2006; Winkelman et al., 2015). We infer that production of long RNAs by reiterative transcription initiation exploits the same cavity within the RNAP active-center cleft (providing an alternative RNA path) and the same opening 
from the RNAP active-center cleft (providing an alternative RNA exit) that exist to accommodate and extrude scrunched nontemplate-strand DNA in standard transcription initiation.

Two changes in RNAP conformation present in the structure obtained following reiterative transcription initiation in solution (Figures 3-4), but not in structures obtained following reiterative transcription initiation in crystallo (Figures 1-2; Murakami et al., 2017; Shin et al., 2020), account for the ability to produce long RNAs in the former, but not in the latter. First, in the structure of RPrtc, $\geq 11$ $\left[\mathrm{C}_{+1} \mathrm{C}_{+2} \mathrm{C}_{+3}\right]$, the tip of the $\sigma$ finger folds back on itself, moving $\sim 3 \AA$ farther away from the RNAP active center (Figures 3B, right and 4D), in a manner similar to, but less marked than, the folding back of the tip of the $\sigma$ finger, driven by collision with the RNA 5' end, that occurs in standard transcription initiation upon extension of the RNA product to a length of 6 nt (Figure 4D; Li et al., 2020). This change in local conformation of the $\sigma$-finger tip enables reiteratively transcribed RNA to enter into the alternative RNA pathway and to be extended beyond a length of $5 \mathrm{nt}$. Second, in the structure of RPrtc, $\geq 11\left[\mathrm{C}_{+1} \mathrm{C}_{+2} \mathrm{C}_{+3}\right]$, the RNAP clamp (Chakraborty et al., 2012; Duchi et al., 2018; Mazumder et al., 2020) opens by $\sim 3^{\circ}$, increasing the width of the RNAP active-center cleft by $\sim 2 \AA$ (Figure $4 \mathrm{E}$ ). This change in RNAP clamp conformation enables reiteratively transcribed RNA to cross nontemplate-strand DNA in order to access the alternative RNA exit and leave the RNAP active-center cleft. In our crystal structures of complexes obtained following reiterative transcription initiation in crystallo, neither of these two conformational changes occurred, and RNA products therefore were limited to lengths of 4-5 nt (Figure 1C-D). In other crystal structures obtained following reiterative transcription initiation in crystallo, using different sequences and different conditions, the first, but not the second, of these two conformational changes occurred, and RNA products therefore were limited to lengths of 6-8 nt (Murakami et al., 2017; Shin et al., 2020).

Mapping of RNAP leading-edge and trailing-edge positions in RPrtc: RNA extension without DNA scrunching 
DNA scrunching by RNAP has two biochemically detectable hallmarks: (i) downstream movement of the RNAP leading edge, but not the RNAP trailing edge, relative to DNA (Kapanidis et al., 2006; Winkelman et al., 2016a; Winkelman and Gourse, 2017; Winkelman et al., 2016b; Yu et al., 2017), and (ii) expansion of the transcription bubble (Revyakin et al., 2006; Yu et al., 2017). In a preceding section, we proposed that RNA extension in reiterative transcription does not involve DNA scrunching, except for 1 bp of DNA scrunching to position the 3' end of the initial RNA product in the RNAP active-center P site. As a first approach to test this proposal, we assessed positions of the RNAP leading edge and trailing edge relative to DNA during reiterative transcription initiation (Figure 5).

We used unnatural amino-acid mutagenesis to incorporate the photoactivatable amino acid p-benzoyl-L-phenylalanine (Bpa) at the RNAP leading edge and trailing edge, and we used protein-DNA photocrosslinking to define positions of the RNAP leading edge and trailing edge relative to DNA (methods essentially as in Winkelman et al., 2016b; Yu et al., 2017). We analyzed reiterative transcription initiation at derivatives of the bacteriophage $\mathrm{N} 25$ promoter containing either a template-strand $\mathrm{G}_{+1} \mathrm{G}_{+2} \mathrm{G}_{+3}$ homopolymeric sequence (RPo $\left[\mathrm{G}_{+1} \mathrm{G}_{+2} \mathrm{G}_{+3}\right]$ and RPrtc $\left[\mathrm{G}_{+1} \mathrm{G}_{+2} \mathrm{G}_{+3}\right]$ ) or a template-strand $\mathrm{C}_{+1} \mathrm{C}_{+2} \mathrm{C}_{+3}$ homopolymeric sequence ( $\mathrm{RPo}\left[\mathrm{C}_{+1} \mathrm{C}_{+2} \mathrm{C}_{+3}\right]$ and $\left.\mathrm{RPrtc}\left[\mathrm{C}_{+1} \mathrm{C}_{+2} \mathrm{C}_{+3}\right]\right)$. For reference, we analyzed standard transcription initiation at the wild-type N25 promoter (RPo WT and RPitc WT). In vitro transcription experiments, carried out using the same reaction conditions, show production of long, up to at least $50 \mathrm{nt}$, reiterative transcripts with the $\mathrm{G}_{+1} \mathrm{G}_{+2} \mathrm{G}_{+3}$ and $\mathrm{C}_{+1} \mathrm{C}_{+2} \mathrm{C}_{+3}$ promoters in the presence of CTP and GTP, respectively, and show production of short, up to $\sim 8 \mathrm{nt}$, standard transcripts with the WT promoter in the presence of ATP and UTP (Figure S1B; Hsu et al., 2003; Revyakin et al., 2006).

The photocrosslinking results indicate that RPrtc exhibits an RNAP trailing-edge position that is unchanged as compared to RPo, exhibits an RNAP leading-edge position that is shifted downstream by 1 bp as compared to RPo of only $1 \mathrm{bp}$, and thus exhibits an RNAP trailing-edge/leading-edge distance that is increased by 1 bp as compared to RPo (Figure 5A). In contrast, RPitc exhibits an RNAP trailing-edge position that is unchanged as compared to RPo, exhibits an RNAP leading-edge position that is shifted downstream by up to $6 \mathrm{bp}$ (range $=1-6 \mathrm{bp}$; mode $=3 \mathrm{bp}$ ) as compared to RPo, and thus exhibits an RNAP 
trailing-edge/leading-edge distance that is increased by up to 6 bp as compared to RPo (range of increase $=1-6 \mathrm{bp}$; modal increase $=3 \mathrm{bp}$; Figure $5 \mathrm{~A})$. An increase in RNAP trailing-edge/leading-edge distance is a defining hallmark of DNA scrunching (Kapanidis et al., 2006; Winkelman et al., 2016b; Yu et al., 2017). Thus, the results indicate that RPrtc engaged in synthesis of RNA products up to at least $50 \mathrm{nt}$ in length exhibits only 1 bp of DNA scrunching, whereas RPitc engaged in synthesis of RNA up to 8 nt in length exhibits up to $6 \mathrm{bp}$ of DNA scrunching. We conclude, consistent with the crystal structures of the preceding sections, that in reiterative transcription--following synthesis of a $2 \mathrm{nt}$ initial RNA product and 1 bp of DNA scrunching to position the 3' end of the initial RNA product in the RNAP active-center P site--RNA extension does not involve DNA scrunching (Figure 5B).

\section{Measurement of transcription bubble size in RPrtc: RNA extension without DNA scrunching}

As a second approach to test the proposal that RNA extension in reiterative transcription does not involve DNA scrunching--except for 1 bp of DNA scrunching to position the 3' end of the initial RNA product in the RNAP active-center P site--we assessed transcription-bubble expansion during reiterative transcription initiation (Figure 6).

We used magnetic-tweezers single-molecule DNA-nanomanipulation to assess reiterative transcription (Figure 6A-B), analyzing the same promoter derivatives as in the preceding section (Figures 5, S1B). The resulting transition amplitudes, transition-amplitude histograms, and RNAP-dependent DNA unwinding values show that RNAP-dependent DNA unwinding is greater by $1 \pm 0.4 \mathrm{bp}$ in RPrtc engaged in synthesis of RNA products up to at least $50 \mathrm{nt}$ in length than in RPo (Figure 6C-E). In contrast, RNAP-dependent DNA unwinding is greater by $5 \pm 0.4$ bp in RPitc engaged in synthesis of RNA products up to $\sim 8 \mathrm{nt}$ than in RPo (Figure $6 \mathrm{C}-\mathrm{E}$ ). An increase in transcription-bubble size is a defining hallmark of DNA scrunching (Revyakin et al., 2006; Yu et al., 2017). Thus, the results from single-molecule DNA nanomanipulation indicate that RPrtc engaged in synthesis of RNA products up to at least $50 \mathrm{nt}$ in length exhibits only $1 \mathrm{bp}$ of DNA scrunching. We conclude, consistent with the conclusions of the preceding sections, that, in reiterative transcription--following synthesis of a 2-nt initial RNA product and 1 bp of 
DNA scrunching to position the 3' end of the initial RNA product in the RNAP active-center P site--RNA extension does not involve DNA scrunching.

\section{Discussion}

\section{Mechanism of reiterative transcription}

Taken together, our results from x-ray crystallography (Figures 1-2), cryo-EM (Figures 3-4), site-specific protein-DNA photocrosslinking (Figure 5), and DNA single-molecule nanomanipulation (Figure 6) establish that, whereas standard transcription initiation involves $1 \mathrm{bp}$ of DNA scrunching for each step of RNA extension, reiterative transcription initiation at promoters containing template-strand $\mathrm{G}_{+1} \mathrm{G}_{+2} \mathrm{G}_{+3}$ and $\mathrm{C}_{+1} \mathrm{C}_{+2} \mathrm{C}_{+3}$ homopolymeric sequences involves only 1 bp of DNA scrunching, irrespective of the number of steps of RNA extension. We conclude that, in reiterative transcription initiation at promoters containing template-strand $\mathrm{G}_{+1} \mathrm{G}_{+2} \mathrm{G}_{+3}$ and $\mathrm{C}_{+1} \mathrm{C}_{+2} \mathrm{C}_{+3}$ homopolymeric sequences, following synthesis of the initial 2 nt RNA product (Figure 7, left, lines 1-2), 1 bp of DNA scrunching occurs to place the RNA 3' end in the RNAP active-center P site (Figure 7, left, lines 2-3), and no additional DNA scrunching occurs in RNA extension (Figure 7, right). We infer that, in reiterative transcription initiation, RNA extension does not involve movement of DNA relative to the RNAP active center, but, instead, involves RNA slipping, in which, in each step of RNA extension, RNA slips upstream by 1 nt relative to both template-strand DNA and the RNAP active center to place the RNA 3' end in the RNAP active-center P site (Figure 7, right). Thus, we infer that, in RNA extension in reiterative transcription initiation, the nucleotide addition cycle consists of RNA slipping to convert a pre-translocated state having a 3 bp RNA-DNA hybrid and having the RNA 3' end in the RNAP active-center A site (“pre-slipped” state; Figure 7, left, RPitc,3 pre and Figure 7, right, RPrtc,n pre) into a post-translocated state having a 2 bp RNA-DNA hybrid and having the RNA 3' end in the RNAP active-center P site (“post-slipped" state; Figure 7, right, RPrtc,n post), followed by NTP binding, phosphodiester bond formation, and pyrophosphate release (Figure 7, right). Thus, in contrast to standard transcription initiation, in which the RNA-DNA hybrid increases in length by 1 bp in each step of RNA extension, up 
to a length of $\sim 10 \mathrm{bp}$, at which point promoter escape ensues (Figure 7, left; Hsu et al., 2003; Mazumder and Kapanidis, 2019; Ruff et al., 2015; Winkelman et al., 2021), in reiterative transcription initiation, the RNA-DNA hybrid does not extend beyond a 3 bp state, and, instead, alternates between a 3 bp pre-slipped state and a 2 bp post-slipped state in each step of RNA extension (Figure 7, right). RNA slipping by $1 \mathrm{nt}$ breaks 1 bp of the RNA-DNA hybrid--specifically the upstream-most base pair of the RNA-DNA hybrid (Figure 7, right); breakage of the upstream-most base pair of the RNA-DNA hybrid occurs because slipping moves the RNA nucleotide that had been base-paired to the upstream-most nucleotide of the template-strand homopolymeric sequence into alignment with a non-complementary DNA nucleotide upstream of the template-strand homopolymeric sequence (Figure 7, right). According to this mechanism, the "branching point," or "decision point," between the standard-transcription-initiation and reiterative-transcription-initiation pathways occurs upon formation of RPitc,3 pre (Figure 7, lines 4-5; at this decision point, DNA scrunching followed by RNA extension yields standard transcription initiation, whereas RNA slipping followed by RNA extension yields reiterative transcription initiation (Figure 7, lines 4-5).

The mechanism for reiterative trascription initiation defined here and set forth in Figure 7 , requires a template-strand homopolymeric sequence at least $3 \mathrm{nt}$ in length. This aspect of the mechanism is consistent with, and supported by, the observation from previous work that reiterative transcription initiation is efficient only at promoters containing template-strand homopolymeric sequences at least $3 \mathrm{nt}$ in length (Cheng et al., 2001; Turnbough and Switzer, 2008; Turnbough Jr, 2011; Vvedenskaya et al., 2015; Xiong and Reznikoff, 1993).

Our results from cryo-EM structure determination of RPrtc, $\geq 11\left[\mathrm{C}_{+1} \mathrm{C}_{+2} \mathrm{C}_{+3}\right]$ (Figures 3-4) further show that production of long, $\geq 11 \mathrm{nt}$, RNAs by reiterative transcription initiation involves an alternative RNA path for nucleotides rN6-rN11 and an alternative RNA exit for nucleotides $r N \geq 11$ (Figures 3A-B,D and 4C). The alternative RNA path exploits the cavity within the RNAP active-center cleft that accommodates scrunched nontemplate-strand DNA in standard transcription initiation (Figure 1B; Basu 
et al., 2014; Hasemeyer, 2018; Kapanidis et al., 2006; Winkelman et al., 2015), and the alternative RNA exit exploits the portal between the RNAP active-center cleft and bulk solvent that mediates the extrusion of long segments of scrunched nontemplate-strand DNA in standard transcription initiation (Hasemeyer, 2018; Kapanidis et al., 2006; Winkelman et al., 2015). Because reiterative transcription initiation involves only $1 \mathrm{bp}$ of DNA scrunching (Figures 1C-D, 3A-C, and 5-7), this cavity within the RNAP active-center cleft and this portal between the RNAP active-center cleft and bulk solvent--both of which would be occupied by scrunched nontemplate-strand DNA in standard transcription initiation--are not occupied by scrunched nontemplate-strand DNA in reiterative transcription and, instead, are available to be occupied by RNA.

A small change in local conformation of the $\sigma$-finger tip--a folding back of the $\sigma$-finger tip upon itself--enables reiteratively transcribed RNA to enter the alternative RNA path, thereby enabling the extension of reiteratively transcribed RNA beyond a length of $5 \mathrm{nt}$ (Figure 4D). A small change in RNAP clamp conformation--an opening of the RNAP clamp by $\sim 3^{\circ}$--enables reiteratively transcribed RNA to cross the nontemplate DNA strand and to access the alternative RNA exit, thereby enabling the extension of reiteratively transcribed RNA beyond a length of $8 \mathrm{nt}$ and the extrusion of reiteratively transcribed RNA from the RNAP active-center cleft (Figure 4E).

Because the alternative RNA path and the alternative RNA exit enable reiteratively transcribed RNA to be extruded from the RNAP active-center cleft without substantially disrupting $\sigma$-DNA and $\sigma$-RNAP interactions (Figure 3A-B), these features enable reiterative transcription initiation to generate long RNAs without promoter escape.

Because most protein-RNA interactions in the alternative RNA path and alternative RNA exit involve interactions with the RNA sugar-phosphate backbone (Figure 4C), and because interactions with RNA bases involve only single H-bonds that likely could be made, with wobble, by any RNA nucleotide (Figure 4C), the alternative RNA path and alternative RNA exit are likely to be compatible with any RNA sequence. 
Because the RNAP and $\sigma$ residues that make protein-RNA interactions with RNA in the alternative RNA path and alternative RNA exit are invariant or highly conserved across Gram-negative, Gram-positive, and Thermnus-Deinococcus-clade bacteria (Figure S3), the alternative RNA path and alternative RNA exit, and the mechanism of reiterative transcription initiation set forth here and in Figure 7, are likely to be conserved across bacterial species.

\section{Prospect}

The results and mechanism of this work, pertain to reiterative transcription initiation at promoters containing template-strand $\mathrm{G}_{+1} \mathrm{G}_{+2} \mathrm{G}_{+3}$ and $\mathrm{C}_{+1} \mathrm{C}_{+2} \mathrm{C}_{+3}$ homopolymeric sequences (Figures 1-7). Previous work shows that reiterative transcription initiation also occurs efficiently at promoters containing template-strand $\mathrm{A}_{+1} \mathrm{~A}_{+2} \mathrm{~A}_{+3}$ and $\mathrm{T}_{+1} \mathrm{~T}_{+2} \mathrm{~T}_{+3}$ homopolymeric sequences (Turnbough and Switzer, 2008; Turnbough Jr, 2011; Vvedenskaya et al., 2015) and at promoters containing $\geq 4 \mathrm{nt}$ homopolymeric sequences (Turnbough and Switzer, 2008; Turnbough Jr, 2011; Vvedenskaya et al., 2015). We consider it likely that the mechanism of Figure 7 also applies to these promoters. Previous work also shows that reiterative transcription initiation can occur at promoters containing more complex, non-homopolymeric repeat sequences (Turnbough and Switzer, 2008; Turnbough Jr, 2011; Vvedenskaya et al., 2015). We consider it likely that a mechanism related to the mechanism of Figure 7, but with different extents of DNA scrunching and RNA slipping, applies at these promoters. We note that the crystal-structure determination, cryo-EM structure determination, site-specific protein-DNA photocrosslinking, and single-molecule nanomanipulation procedures of this report could be used to define mechanisms of reiterative transcription at any promoter.

Previous work has shown that complexes engaged in reiterative transcription initiation synthesizing RNA products up to at least $8 \mathrm{nt}$ in length can switch from reiterative transcription initiation to standard transcription initiation, yielding productive complexes that escape the promoter and synthesize full-length RNA products comprising non-templated, reiterative-transcription-dependent nucleotides at their 5' ends followed by templated, standard-transcription-dependent nucleotides 
(Turnbough and Switzer, 2008; Turnbough Jr, 2011; Vvedenskaya et al., 2015). Key unresolved questions include how this switching occurs and where the RNA products that result from switching exit the RNAP active-center cleft. We hypothesize that RNA products that result from switching exit the RNAP active-center cleft through the RNAP RNA-exit channel, with the templated RNA segment generated after switching to standard transcription initiation proceeding into, and through, the RNAP RNA-exit channel as in standard transcription, and pulling the 5' non-templated RNA segment behind it. According to this hypothesis, the RNA product that results from switching would proceed into, and through, the RNAP RNA-exit channel as an RNA loop, and would trigger promoter escape by displacing the $\sigma$ region-3/region-4 linker from the RNA-exit channel as in standard transcription (Figure S4, right). Cryo-EM structures of transcription complexes containing double-stranded RNA in the RNAP RNA-exit channel verify that the dimensions of the RNAP RNA-exit channel could accommodate such an RNA loop (Guo et al., 2018; Kang et al., 2018). Cryo-EM structure determination, analyzing transcription elongation complexes containing 5' non-templated RNA segments generated by switching from reiterative transcription initiation to standard transcription initiation, potentially could provide a means to test this hypothesis. 


\section{Acknowledgements}

Work was supported by National Institutes of Health grants GM118059 (BEN) and GM041376 (RHE) and National Natural Science Foundation of China grant 31822001 (YZ).

\section{Competing interests}

The authors declare no competing interests.

\section{Author Contributions}

Conceptualization, Y.L., J.T.W., L.Y., Y.Z., B.E.N., and R.H.E.; Investigation, Y.L., J.T.W., L.Y., C.P., E.F., J.T.K., and Y.Z.; Formal Analysis, Y.L., J.T.W., L.Y., and Y.Z.; Writing, Y.L., J.T.W., B.E.N., and R.H.E.; Visualization, Y.L., J.T.W., B.E.N., and R.H.E.; Supervision, B.E.N. and R.H.E.; Project Administration, B.E.N. and R.H.E.; Funding Acquisition, Y.Z., B.E.N. and R.H.E. 


\section{References}

Basu, R.S., Warner, B.A., Molodtsov, V., Pupov, D., Esyunina, D., Fernandez-Tornero, C., Kulbachinskiy, A., and Murakami, K.S. (2014). Structural basis of transcription initiation by bacterial RNA polymerase holoenzyme. J Biol Chem 289, 24549-24559.

Chakraborty, A., Wang, D., Ebright, Y.W., Korlann, Y., Kortkhonjia, E., Kim, T., Chowdhury, S., Wigneshweraraj, S., Irschik, H., Jansen, R., et al. (2012). Opening and closing of the bacterial RNA polymerase clamp. Science 337, 591-595.

Chamberlin, M., and Berg, P. (1962). Deoxyribo ucleic acid-directed synthesis of ribonucleic acid by an enzyme from Escherichia coli. Proc Natl Acad Sci U.S.A. 48, 81-94.

Chamberlin, M., and Berg, P. (1964). Mechanism of Rna Polymerase Action: Characterization of the DNA-Dependent Synthesis of Polyadenylic Acid. J Mol Biol 8, 708-726.

Chen, J., Boyaci, H., and Campbell, E.A. (2021). Diverse and unified mechanisms of transcription initiation in bacteria. Nat Rev Microbiol 19, 95-109.

Cheng, Y., Dylla, S.M., and Turnbough, C.L., Jr. (2001). A long T. A tract in the upp initially transcribed region is required for regulation of upp expression by UTP-dependent reiterative transcription in Escherichia coli. J Bacteriol 183, 221-228.

Chin, J.W., Martin, A.B., King, D.S., Wang, L., and Schultz, P.G. (2002). Addition of a photocrosslinking amino acid to the genetic code of Escherichia coli. Proc Natl Acad Sci U.S.A. 99, $11020-11024$.

Chlenov, M., Masuda, S., Murakami, K.S., Nikiforov, V., Darst, S.A., and Mustaev, A. (2005). Structure and function of lineage-specific sequence insertions in the bacterial RNA polymerase beta' subunit. J Mol Biol 353, 138-154.

Duchi, D., Mazumder, A., Malinen, A.M., Ebright, R.H., and Kapanidis, A.N. (2018). The RNA polymerase clamp interconverts dynamically among three states and is stabilized in a partly closed state by ppGpp. Nucleic Acids Res 46, 7284-7295.

Emsley, P., Lohkamp, B., Scott, W.G., and Cowtan, K. (2010). Features and development of Coot. Acta Crystallogr D Biol Crystallogr 66, 486-501.

Feklistov, A., Sharon, B.D., Darst, S.A., and Gross, C.A. (2014). Bacterial sigma factors: a historical, structural, and genomic perspective. Annu Rev Microbiol 68, 357-376.

Feng, Y., Zhang, Y., and Ebright, R.H. (2016). Structural basis of transcription activation. Science 352, $1330-1333$.

Guo, H.C., and Roberts, J.W. (1990). Heterogeneous initiation due to slippage at the bacteriophage 82 late gene promoter in vitro. Biochemistry 29, 10702-10709. 
Guo, X., Myasnikov, A.G., Chen, J., Crucifix, C., Papai, G., Takacs, M., Schultz, P., and Weixlbaumer, A. (2018). Structural Basis for NusA Stabilized Transcriptional Pausing. Mol Cell 69, 816-827 e814.

Han, X., and Turnbough, C.L., Jr. (1998). Regulation of carAB expression in Escherichia coli occurs in part through UTP-sensitive reiterative transcription. J Bacteriol 180, 705-713.

Hasemeyer, A. (2018). Mechanism of DNA scrunching during initial transcription. In School of Graduate Studies (Rutgers University).

Hsu, L.M., Vo, N.V., Kane, C.M., and Chamberlin, M.J. (2003). In vitro studies of transcript initiation by Escherichia coli RNA polymerase. 1. RNA chain initiation, abortive initiation, and promoter escape at three bacteriophage promoters. Biochemistry 42, 3777-3786.

Jacques, J.P., and Kolakofsky, D. (1991). Pseudo-templated transcription in prokaryotic and eukaryotic organisms. Genes Dev 5, 707-713.

Jensen-MacAllister, I.E., Meng, Q., and Switzer, R.L. (2007). Regulation of pyrG expression in Bacillus subtilis: CTP-regulated antitermination and reiterative transcription with pyrG templates in vitro. Mol Microbiol 63, 1440-1452.

Kang, J.Y., Mishanina, T.V., Bellecourt, M.J., Mooney, R.A., Darst, S.A., and Landick, R. (2018). RNA Polymerase Accommodates a Pause RNA Hairpin by Global Conformational Rearrangements that Prolong Pausing. Mol Cell 69, 802-815 e805.

Kapanidis, A.N., Margeat, E., Ho, S.O., Kortkhonjia, E., Weiss, S., and Ebright, R.H. (2006). Initial transcription by RNA polymerase proceeds through a DNA-scrunching mechanism. Science 314, 11441147.

Lane, W.J., and Darst, S.A. (2010). Molecular evolution of multisubunit RNA polymerases: sequence analysis. J Mol Biol 395, 671-685.

Li, L., Molodtsov, V., Lin, W., Ebright, R.H., and Zhang, Y. (2020). RNA extension drives a stepwise displacement of an initiation-factor structural module in initial transcription. Proc Natl Acad Sci U.S.A. $117,5801-5809$.

Liebschner, D., Afonine, P.V., Baker, M.L., Bunkoczi, G., Chen, V.B., Croll, T.I., Hintze, B., Hung, L.W., Jain, S., McCoy, A.J., et al. (2019). Macromolecular structure determination using X-rays, neutrons and electrons: recent developments in Phenix. Acta Crystallogr D Struct Biol 75, 861-877.

Lionnet, T., Allemand, J.F., Revyakin, A., Strick, T.R., Saleh, O.A., Bensimon, D., and Croquette, V. (2012). Magnetic trap construction. Cold Spring Harb Protoc 2012, 133-138.

Liu, C., Heath, L.S., and Turnbough, C.L., Jr. (1994). Regulation of pyrBI operon expression in Escherichia coli by UTP-sensitive reiterative RNA synthesis during transcriptional initiation. Genes \& development 8, 2904-2912.

Macdonald, L.E., Zhou, Y., and McAllister, W.T. (1993). Termination and slippage by bacteriophage T7 RNA polymerase. J Mol Biol 232, 1030-1047. 
Maffioli, S.I., Zhang, Y., Degen, D., Carzaniga, T., Del Gatto, G., Serina, S., Monciardini, P., Mazzetti, C., Guglierame, P., Candiani, G., et al. (2017). Antibacterial Nucleoside-Analog Inhibitor of Bacterial RNA Polymerase. Cell 169, 1240-1248 e1223.

Margeat, E., Kapanidis, A.N., Tinnefeld, P., Wang, Y., Mukhopadhyay, J., Ebright, R.H., and Weiss, S. (2006). Direct observation of abortive initiation and promoter escape within single immobilized transcription complexes. Biophys J 90, 1419-1431.

Marr, M.T., and Roberts, J.W. (1997). Promoter recognition as measured by binding of polymerase to nontemplate strand oligonucleotide. Science 276, 1258-1260.

Mastronarde, D. (2018). Advanced Data Acquisition From Electron Microscopes With SerialEM. Microscopy and Microanalysis 24, 864-865.

Mazumder, A., and Kapanidis, A.N. (2019). Recent Advances in Understanding sigma70-Dependent Transcription Initiation Mechanisms. J Mol Biol 431, 3947-3959.

Mazumder, A., Lin, M., Kapanidis, A.N., and Ebright, R.H. (2020). Closing and opening of the RNA polymerase trigger loop. Proc Natl Acad Sci U.S.A. 117, 15642-15649.

Mekler, V., Kortkhonjia, E., Mukhopadhyay, J., Knight, J., Revyakin, A., Kapanidis, A.N., Niu, W., Ebright, Y.W., Levy, R., and Ebright, R.H. (2002). Structural organization of bacterial RNA polymerase holoenzyme and the RNA polymerase-promoter open complex. Cell 108, 599-614.

Meng, Q., Turnbough, C.L., Jr., and Switzer, R.L. (2004). Attenuation control of pyrG expression in Bacillus subtilis is mediated by CTP-sensitive reiterative transcription. Proc Natl Acad Sci U.S.A. 101, 10943-10948.

Minor, W., Cymborowski, M., Otwinowski, Z., and Chruszcz, M. (2006). HKL-3000: the integration of data reduction and structure solution--from diffraction images to an initial model in minutes. Acta Crystallogr D Biol Crystallogr 62, 859-866.

Murakami, K.S., Masuda, S., Campbell, E.A., Muzzin, O., and Darst, S.A. (2002a). Structural basis of transcription initiation: an RNA polymerase holoenzyme-DNA complex. Science 296, 1285-1290.

Murakami, K.S., Masuda, S., and Darst, S.A. (2002b). Structural basis of transcription initiation: RNA polymerase holoenzyme at 4 A resolution. Science 296, 1280-1284.

Murakami, K.S., Shin, Y., Turnbough, C.L., Jr., and Molodtsov, V. (2017). X-ray crystal structure of a reiterative transcription complex reveals an atypical RNA extension pathway. Proceedings of the National Academy of Sciences of the United States of America 114, 8211-8216.

Pantelic R.S., Meyer J.C., Kaiser U., Baumeister W., and Plitzko J.M. (2010). Graphene oxide: a substrate for optimizing preparations of frozen-hydrated samples. J. Struct. Biol. 170, 152-156.

Qi, F., and Turnbough, C.L., Jr. (1995). Regulation of codBA operon expression in Escherichia coli by UTP-dependent reiterative transcription and UTP-sensitive transcriptional start site switching. J Mol Biol 254, 552-565. 
Revyakin, A., Allemand, J.F., Croquette, V., Ebright, R.H., and Strick, T.R. (2003). Single-molecule DNA nanomanipulation: detection of promoter-unwinding events by RNA polymerase. Methods Enzymol 370, 577-598.

Revyakin, A., Ebright, R.H., and Strick, T.R. (2004). Promoter unwinding and promoter clearance by RNA polymerase: detection by single-molecule DNA nanomanipulation. Proc Natl Acad Sci U.S.A. 101, 4776-4780.

Revyakin, A., Ebright, R.H., and Strick, T.R. (2005). Single-molecule DNA nanomanipulation: improved resolution through use of shorter DNA fragments. Nat Methods 2, 127-138.

Revyakin, A., Liu, C., Ebright, R.H., and Strick, T.R. (2006). Abortive initiation and productive initiation by RNA polymerase involve DNA scrunching. Science 314, 1139-1143.

Rohou, A., and Grigorieff, N. (2015). CTFFIND4: Fast and accurate defocus estimation from electron micrographs. J Struct Biol 192, 216-221.

Ruff, E.F., Record, M.T., Jr., and Artsimovitch, I. (2015). Initial events in bacterial transcription initiation. Biomolecules 5, 1035-1062.

Sambrook, J., and Russell, D.W. (2006). The condensed protocols from Molecular cloning : a laboratory manual (Cold Spring Harbor, N.Y.: Cold Spring Harbor Laboratory Press).

Severinov, K., and Goldfarb, A. (1994). Topology of the product binding site in RNA polymerase revealed by transcript slippage at the phage lambda PL promoter. J Biol Chem 269, 31701-31705.

Shin, Y., Hedglin, M., and Murakami, K.S. (2020). Structural basis of reiterative transcription from the pyrG and pyrBI promoters by bacterial RNA polymerase. Nucleic Acids Res 48, 2144-2155.

Svetlov, V., and Artsimovitch, I. (2015). Purification of bacterial RNA polymerase: tools and protocols. Methods Mol Biol 1276, 13-29.

Thomas, G.M., Andreas, B., Anthony, W.P., and Sjors H.W., (2016). Graphene Oxide Grid Preparation.

Tu, A.H., and Turnbough, C.L., Jr. (1997). Regulation of upp expression in Escherichia coli by UTPsensitive selection of transcriptional start sites coupled with UTP-dependent reiterative transcription. J Bacteriol 179, 6665-6673.

Turnbough, C.L., Jr. (2019). Regulation of Bacterial Gene Expression by Transcription Attenuation. Microbiol Mol Biol Rev 83.

Turnbough, C.L., and Switzer, R.L. (2008). Regulation of pyrimidine biosynthetic gene expression in bacteria: repression without repressors. Microbiol Mol Biol Rev 72, 266-300.

Turnbough Jr, C.L. (2011). Regulation of gene expression by reiterative transcription. Curr Opin Microbiol 14, 142-147.

Vassylyev, D.G., Sekine, S., Laptenko, O., Lee, J., Vassylyeva, M.N., Borukhov, S., and Yokoyama, S. (2002). Crystal structure of a bacterial RNA polymerase holoenzyme at $2.6 \AA$ resolution. Nature 417 , 712-719. 
Vvedenskaya, I.O., Zhang, Y., Goldman, S.R., Valenti, A., Visone, V., Taylor, D.M., Ebright, R.H., and Nickels, B.E. (2015). Massively Systematic Transcript End Readout, "MASTER": Transcription Start Site Selection, Transcriptional Slippage, and Transcript Yields. Mol Cell 60, 953-965.

Wagner, L.A., Weiss, R.B., Driscoll, R., Dunn, D.S., and Gesteland, R.F. (1990). Transcriptional slippage occurs during elongation at runs of adenine or thymine in Escherichia coli. Nucleic Acids Res 18, 35293535 .

Wang, J.C. (1979). Helical repeat of DNA in solution. Proc Natl Acad Sci U.S.A. 76, 200-203.

Winkelman, J.T., Chandrangsu, P., Ross, W., and Gourse, R.L. (2016a). Open complex scrunching before nucleotide addition accounts for the unusual transcription start site of E. coli ribosomal RNA promoters. Proceedings of the National Academy of Sciences 113, E1787-E1795.

Winkelman, J.T., and Gourse, R.L. (2017). Open complex DNA scrunching: a key to transcription start site selection and promoter escape. BioEssays 39, 1600193.

Winkelman, J.T., Nickels, B.E., and Ebright, R.H. (2021). The transition from transcription initiation to transcription elongation: start-site selection, initial transcription, and promoter escape. In RNA Polymerase as a Molecular Motor, Second Edition, R. Landick, J. Wang, and T.R. Strick, eds. (Cambridge, UK: RSC Publishing).

Winkelman, J.T., Vvedenskaya, I.O., Zhang, Y., Zhang, Y., Bird, J.G., Taylor, D.M., Gourse, R.L., Ebright, R.H., and Nickels, B.E. (2016b). Multiplexed protein-DNA cross-linking: Scrunching in transcription start site selection. Science 351, 1090-1093.

Winkelman, J.T., Winkelman, B.T., Boyce, J., Maloney, M.F., Chen, A.Y., Ross, W., and Gourse, R.L. (2015). Crosslink Mapping at Amino Acid-Base Resolution Reveals the Path of Scrunched DNA in Initial Transcribing Complexes. Mol Cell 59, 768-780.

Xiong, X.F., and Reznikoff, W.S. (1993). Transcriptional slippage during the transcription initiation process at a mutant lac promoter in vivo. J Mol Biol 231, 569-580.

Yin, Z., Kaelber, J.T., and Ebright, R.H. (2019). Structural basis of Q-dependent antitermination. Proc Natl Acad Sci U.S.A. 116, 18384-18390.

Yu, L., Winkelman, J.T., Pukhrambam, C., Strick, T.R., Nickels, B.E., and Ebright, R.H. (2017). The mechanism of variability in transcription start site selection. eLife 6, e32038.

Zhang, G., Campbell, E.A., Minakhin, L., Richter, C., Severinov, K., and Darst, S.A. (1999). Crystal structure of Thermus aquaticus core RNA polymerase at $3.3 \AA$ resolution. Cell 98, 811-824.

Zhang, Y., Feng, Y., Chatterjee, S., Tuske, S., Ho, M.X., Arnold, E., and Ebright, R.H. (2012). Structural basis of transcription initiation. Science 338, 1076-1080.

Zheng, S.Q., Palovcak, E., Armache, J.P., Verba, K.A., Cheng, Y., and Agard, D.A. (2017). MotionCor2: anisotropic correction of beam-induced motion for improved cryo-electron microscopy. Nat Methods 14, 331-332. 
bioRxiv preprint doi: https://doi.org/10.1101/2021.05.08.443277; this version posted August 14, 2021. The copyright holder for this preprint (which was not certified by peer review) is the author/funder. All rights reserved. No reuse allowed without permission.

Zivanov, J., Nakane, T., Forsberg, B.O., Kimanius, D., Hagen, W.J., Lindahl, E., and Scheres, S.H. (2018). New tools for automated high-resolution cryo-EM structure determination in RELION-3. Elife 7, e42166. 


\section{Figure Legends}

\section{Figure 1. Crystal structures of RPrtc,4 and RPrtc,5: RNA extension through RNA slipping without}

\section{DNA scrunching}

Crystal structures of transcription initiation complexes engaged in standard transcription initiation and reiterative transcription initiation. Left, experimental electron density ( $\mathrm{mFo}-\mathrm{DFc}$; contoured at $2.0 \sigma$ in A and $1.5 \sigma$ in B-D) and atomic model, showing interactions of RNAP and $\sigma$ with transcription-bubble nontemplate strand, transcription-bubble template strand, and downstream dsDNA (RNAP $\beta$ subunit and $\beta$ ' non-conserved domain omitted for clarity). Right, nucleic-acid scaffold. RNAP, gray; RNAP active-center catalytic $\mathrm{Mg}^{2+}(\mathrm{I})$ ion, violet filled circle; $\sigma$, yellow; $\sigma$ finger, asterisk (left subpanel) and yellow-brown (right subpanel); $\sigma \mathrm{R} 3-\sigma \mathrm{R} 4$ linker in RNA exit channel, brown; -10 element of DNA nontemplate strand, dark blue; discriminator element of DNA nontemplate strand, light blue; rest of DNA nontemplate strand, pink; DNA template strand, red; RNA product, magenta. Cyan rectangles on panel B indicate disordered regions containing scrunched nucleotides. Cyan rectangles in panels $\mathrm{C}$ and $\mathrm{D}$ indicate ordered scrunched nucleotides. Bulged-out nucleotides in panels B-D, right, indicate bulged-out scrunched nucleotides. Violet rectangles indicate RNA-DNA hybrids. Raised template-strand nucleotides in panels C-D indicate non-base-paired nucleotides.

(A) RNAP-promoter open complex (RPo; PDB 4G7H; Zhang et al., 2012).

(B) RNAP-promoter initial transcribing complex containing 5 nt RNA product generated by in crystallo standard transcription initiation (RPitc,5).

(C) RNAP-promoter reiteratively transcribing complex containing $5 \mathrm{nt}$ RNA product generated by in crystallo reiterative transcription initiation on nucleic-acid scaffold having a template-strand $\mathrm{G}_{+1} \mathrm{G}_{+2} \mathrm{G}_{+3}$ homopolymeric sequence (RPrtc, $5\left[\mathrm{G}_{+1} \mathrm{G}_{+2} \mathrm{G}_{+3}\right]$ ). 
(D) RNAP-promoter reiteratively transcribing complex containing 4 nt RNA product generated by in crystallo reiterative transcription initiation on nucleic-acid scaffold having a template-strand $\mathrm{C}_{+1} \mathrm{C}_{+2} \mathrm{C}_{+3}$ homopolymeric sequence (RPrtc, $4\left[\mathrm{C}_{+1} \mathrm{C}_{+2} \mathrm{C}_{+3}\right]$ ).

\section{Figure 2. Crystal structures of RPrtc,4 and RPrtc,5: short RNA-DNA hybrid}

(A) RNA-DNA base pairing in crystal structures of transcription initiation complexes engaged in standard transcription initiation (RPitc,5) and reiterative transcription initiation (RPrtc, $5\left[\mathrm{G}_{+1} \mathrm{G}_{+2} \mathrm{G}_{+3}\right]$ and $\mathrm{RPrtc}, 4$ $\left.\left[\mathrm{C}_{+1} \mathrm{C}_{+2} \mathrm{C}_{+3}\right]\right)$. Left, template-strand DNA bases (red) and corresponding RNA bases (magenta) in view orientation parallel to RNA-DNA-hybrid helix axis. Right, template-strand DNA bases (red) and corresponding RNA bases (magenta) in view orientation perpendicular to RNA-DNA-hybrid helix axis. Positions are numbered relative to the RNAP active-center P site. Dashed lines indicate Watson-Crick H-bonds. Violet rectangles indicate RNA-DNA hybrids. At positions P-4, P-3, and P-2 of RPrtc,5 $\left[\mathrm{G}_{+1} \mathrm{G}_{+2} \mathrm{G}_{+3}\right]$, and at positions P-3 and P-2 of RPrtc, $4\left[\mathrm{C}_{+1} \mathrm{C}_{+2} \mathrm{C}_{+3}\right]$, template-strand DNA bases are displaced relative to their locations in RPitc,5, and no base pairing occurs.

(B) Superimposition of DNA template strand and RNA of RPrtc, $5\left[\mathrm{G}_{+1} \mathrm{G}_{+2} \mathrm{G}_{+3}\right]$ (red spheres, DNA phosphates; magenta spheres, RNA phosphates; violet sphere, RNAP active-center catalytic $\mathrm{Mg}^{2+}$ ion) on DNA template strand and RNA of RPitc,5 (gray spheres, DNA and RNA phosphates). Left, view orientation parallel to RNA-DNA-hybrid helix axis; right, view orientation perpendicular to RNA-DNA-hybrid helix axis. Distances in cyan, displacement of template-strand DNA nucleotides at positions P-4 and P-3 of RPrtc, $5\left[\mathrm{G}_{+1} \mathrm{G}_{+2} \mathrm{G}_{+3}\right]$ relative to their locations in RPitc,5.

Figure 3. Cryo-EM structure of RPrtc, $\geq 11$ : RNA extension through RNA slipping without DNA scrunching

(A) Overall structure ( $\beta$ ' nonconserved region omitted for clarity; two orthogonal view orientations).

Dark blue brackets indicate the standard RNA exit and alternative RNA exit. Cyan rectangles indicate 
scrunched nucleotides. Violet rectangles indicate RNA-DNA hybrids. Other symbols and colors in panels A-D are as in Figure 1.

(B) Left, cryo-EM density and atomic model, showing interactions of RNAP and $\sigma$ with transcription-bubble nontemplate strand, transcription-bubble template strand, and downstream dsDNA. Right, nucleic-acid scaffold. Yellow-brown, $\sigma$ finger (note displacement of $\sigma$-finger tip); magenta dots, RNA outside RNAP active-center cleft (nucleotides $\mathrm{rN} \geq 11$ ).

(C) Superimposition of DNA in RPrtc, $\geq 11\left[\mathrm{C}_{+1} \mathrm{C}_{+2} \mathrm{C}_{+3}\right]$ (pink and red) on DNA in RPo (black; PDB 512D; Feng et al., 2016).

(D) Close-up of cryo-EM density and atomic model for RNA (nucleotides rN1-rN11 numbered in white).

\section{Figure 4. Cryo-EM structure of RPrtc, $\geq 11$ : short RNA-DNA hybrid and RNA exit through nontemplate-strand scrunching portal}

(A) RNA-DNA base pairing. Yellow dashed lines, non-Watson-Crick H-bonds. Other symbols and colors as in Figure 2A.

(B) Superimposition of DNA template strand and RNA of RPrtc, $\geq 11\left[\mathrm{C}_{+1} \mathrm{C}_{+2} \mathrm{C}_{+3}\right]$ (red spheres, DNA

phosphates; magenta spheres, RNA phosphates; violet sphere, RNAP active-center catalytic $\mathrm{Mg}^{2+}$ ion) on DNA template strand and RNA of RPitc,5 (gray spheres, DNA and RNA phosphates).

(C) Protein-RNA and DNA-RNA interactions in alternative RNA path. Left, center, and right subpanels show interactions with RNA nucleotides with rN3-rN6, rN6-rN8, and rN9-rN11 (atoms in magenta; nucleotide numbers in white). Ribbons and sticks, backbone segments and sidechain atoms of residues of RNAP $\beta$ (backbone segments in white; carbon oxygen and nitrogen atoms in white, red, and blue) and $\sigma$ (backbone segments in yellow; carbon oxygen and nitrogen atoms in yellow, red, and blue) that make protein-RNA interactions with $\mathrm{rN} 3-\mathrm{rN} 11$. "NT+2," nucleotide at nontemplate-strand position +2 that makes base-stacking interaction with RNA nucleotide rN8. Other colors as in Figure 1. 
(D) $\sigma$-finger conformation. Left, cryo-EM density and atomic model for $\sigma$ finger. Right, superimposition of $\sigma$ finger of RPrtc, $\geq 11\left[\mathrm{C}_{+1} \mathrm{C}_{+2} \mathrm{C}_{+3}\right]$ (yellow) on $\sigma$ finger of RPo (black; PDB 4G7H; Zhang et al., 2012). Other colors as in Figure 1.

(E) RNAP clamp conformation. Superimposition of RNAP of RPrtc, $\geq 11\left[\mathrm{C}_{+1} \mathrm{C}_{+2} \mathrm{C}_{+3}\right]$ (clamp in red; rest of RNAP in gray) on RNAP of RPo (black; PDB 4G7H; Zhang et al., 2012).

\section{Figure 5. Mapping of RNAP leading-edge and trailing-edge positions in RPrtc by use of}

\section{protein-DNA photocrosslinking: RNA extension without DNA scrunching}

(A) RNAP trailing-edge and leading-edge positions in transcription initiation complexes at the N25 promoter (WT) and derivatives of the $\mathrm{N} 25$ promoter containing template-strand $\mathrm{G}_{+1} \mathrm{G}_{+2} \mathrm{G}_{+3}$ and $\mathrm{C}_{+1} \mathrm{C}_{+2} \mathrm{C}_{+3}$ homopolymeric sequences $\left(\mathrm{G}_{+1} \mathrm{G}_{+2} \mathrm{G}_{+3}\right.$ and $\left.\mathrm{C}_{+1} \mathrm{C}_{+2} \mathrm{C}_{+3}\right)$. First bracketed subpanel, protein-DNA photocrosslinking data for RNAP-promoter open complex (RPo); second bracketed subpanel, protein-DNA photocrosslinking data for transcription initiation complexes engaged in standard transcription initiation (RPitc) and reiterative transcription initiation (RPrtc); third bracketed subpanel, interpretation of protein-DNA photocrosslinking data for RPo; fourth bracketed subpanel, interpretation of protein-DNA photocrosslinking data for RPitc and RPrtc. In third and fourth subpanels, promoter sequences are shown with positions numbered relative to the transcription start site, and with positions of the -10-element, the discriminator element, and the homopolymeric sequence highlighted in blue, light blue, and red. Thick and thin light green bars indicate strong and weak RNAP-trailing-edge crosslinks, and thick and thin dark green bars indicate strong and weak RNAP-leading-edge crosslinks. Bottom of panel, observed modal trailing-edge/leading-edge distances (modal TE-LE distance) and differences in modal TE-LE distance relative to modal TE-LE distance in RPo at wild-type N25 promoter [ $\Delta$ (modal TE-LE distance)].

(B) Mechanistic interpretation of data in panel A. Three states are shown: RPo, RPitc [specifically, RPitc having a $5 \mathrm{nt}$ RNA product in a post-translocated state (RPitc, 5 post), corresponding to the major 
crosslink in panel A], and RPrtc. Gray, RNAP; yellow, $\sigma$; yellow-brown, $\sigma$ finger (note displacement of $\sigma$-finger tip in RPrtc); brown, $\sigma$ region-3/region-4 linker; light green, trailing-edge Bpa and crosslinking site for trailing-edge Bpa; dark green, leading-edge Bpa and crosslinking site for leading-edge Bpa; black boxes with blue fill, -10-element nucleotides; black boxes with light blue fill, discriminator-element nucleotides; black boxes with red fill, template-strand homopolymeric-sequence nucleotides; other black boxes, other DNA nucleotides (nontemplate-strand nucleotides above template-strand nucleotides); magenta boxes, RNA nucleotides; violet rectangles, RNA-DNA hybrids; P and A, RNAP active-center product and addition sites. Raised template-strand nucleotides and black x's indicate non-base-paired nucleotides. Scrunching of nontemplate and template DNA strands is indicated by bulged-out nucleotides. Initial-product formation in both standard transcription initiation and reiterative transcription initiation involves one step of DNA scrunching. RNA extension in standard transcription initiation involves additional DNA scrunching, but RNA extension in reiterative transcription does not.

\section{Figure 6. Measurement of transcription bubble size in RPrtc by use of single-molecule DNA} nanomanipulation: RNA extension without DNA scrunching

(A)-(B) Experimental approach (Revyakin et al., 2005; Revyakin et al., 2006; Yu et al., 2017). (A), apparatus. (B), end-to-end extension ( $l$ ) of a mechanically stretched, positively supercoiled (top), or negatively supercoiled (bottom), DNA molecule is monitored. Unwinding of $\mathrm{n}$ turns of DNA by RNAP results in compensatory gain of $\mathrm{n}$ positive supercoils or loss of $\mathrm{n}$ negative supercoils, and movement of the bead by $\mathrm{n} * 56 \mathrm{~nm}$.

(C) Single-molecule time traces for RPo and RPitc at the N25 promoter (WT; left), and for RPo and RPrtc at derivatives of the $\mathrm{N} 25$ promoter containing template-strand $\mathrm{G}_{+1} \mathrm{G}_{+2} \mathrm{G}_{+3}$ and $\mathrm{C}_{+1} \mathrm{C}_{+2} \mathrm{C}_{+3}$ homopolymeric sequences $\left(\mathrm{G}_{+1} \mathrm{G}_{+2} \mathrm{G}_{+3}\right.$ and $\mathrm{C}_{+1} \mathrm{C}_{+2} \mathrm{C}_{+3}$; middle and right). Upper subpanels, positively supercoiled DNA; lower subpanels, negatively supercoiled DNA. Green points, raw data (30 frames/s); red points, averaged data (1 s window); horizontal black lines, unbound and RPo states; dashed horizontal 
black lines, RPitc and RPrtc states (with the difference in $\Delta$ lobs between RPo and RPitc being substantially greater than the difference in $\Delta l_{\text {obs }}$ between RPo and RPrtc).

(D) Single-molecule transition-amplitude histograms for RPo and RPitc at the N25 promoter (WT; left), and for RPo and RPrtc at derivatives of the $\mathrm{N} 25$ promoter containing template-strand $\mathrm{G}_{+1} \mathrm{G}_{+2} \mathrm{G}_{+3}$ and $\mathrm{C}_{+1} \mathrm{C}_{+2} \mathrm{C}_{+3}$ homopolymeric sequences $\left(\mathrm{G}_{+1} \mathrm{G}_{+2} \mathrm{G}_{+3}\right.$ and $\mathrm{C}_{+1} \mathrm{C}_{+2} \mathrm{C}_{+3}$; middle and right). Upper subpanels, positively supercoiled DNA; lower subpanels, negatively supercoiled DNA. Vertical dashed lines, means; $\Delta l$ obs,pos, transition amplitudes with positively supercoiled DNA; $\Delta l$ lobs,neg, transition amplitudes with negatively supercoiled DNA.

(E) Differences in $\Delta l_{\text {obs,pos }}$ and DNA unwinding relative to those in RPo at wild-type N25 promoter (means \pm 2 SEM)

\section{Figure 7. Mechanisms of standard transcription initiation and reiterative transcription initiation.}

Standard transcription initiation (left column) and reiterative transcription initiation (first four panels of left column followed by panels of right column). Cyan, reactions present only in reiterative transcription: i.e., cycles of RNA extension and slippage. Other colors and symbols are as in Figure 5. Scrunching is indicated by bulged-out nucleotides ( 8-10 scrunched bp prior to promoter escape in the standard transcription initiation pathway; 1 scrunched bp in the reiterative transcription initiation pathway). Scrunched nucleotides of nontemplate and template DNA strands during initial transcription are accommodated as bulges within the unwound transcription bubble. 

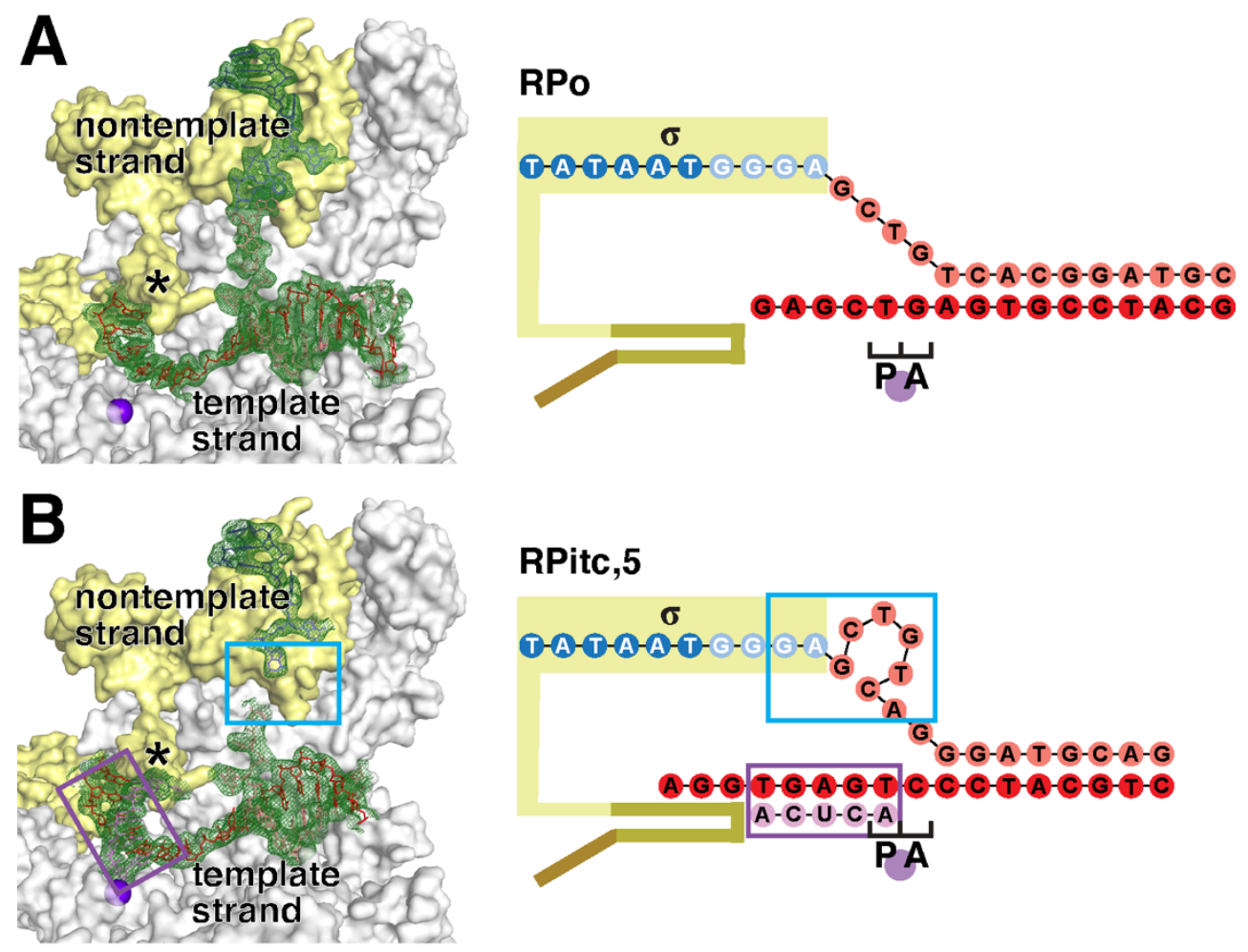

\section{RPitc,5}
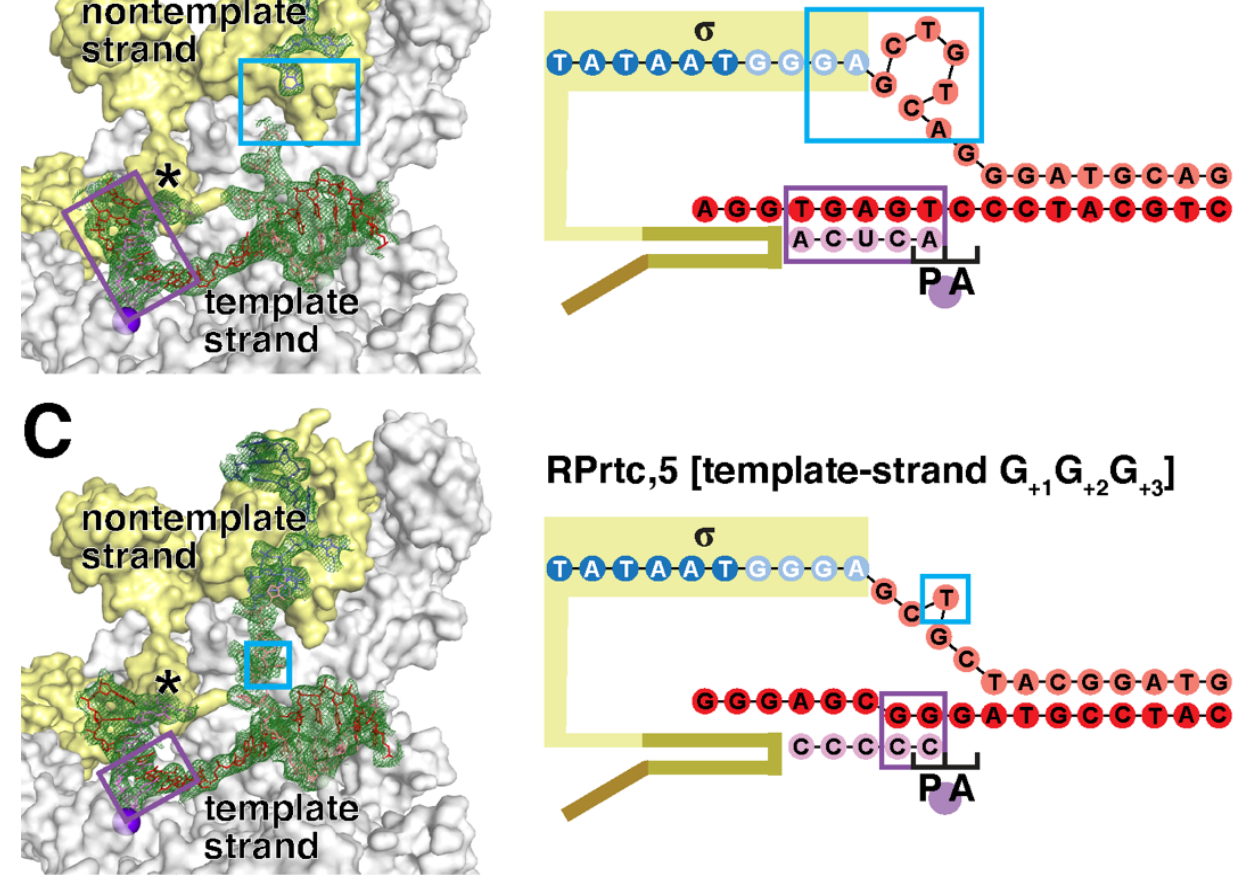

\section{RPrtc,5 [template-strand $\mathbf{G}_{+1} \mathbf{G}_{+2} \mathbf{G}_{+3}$ ]}
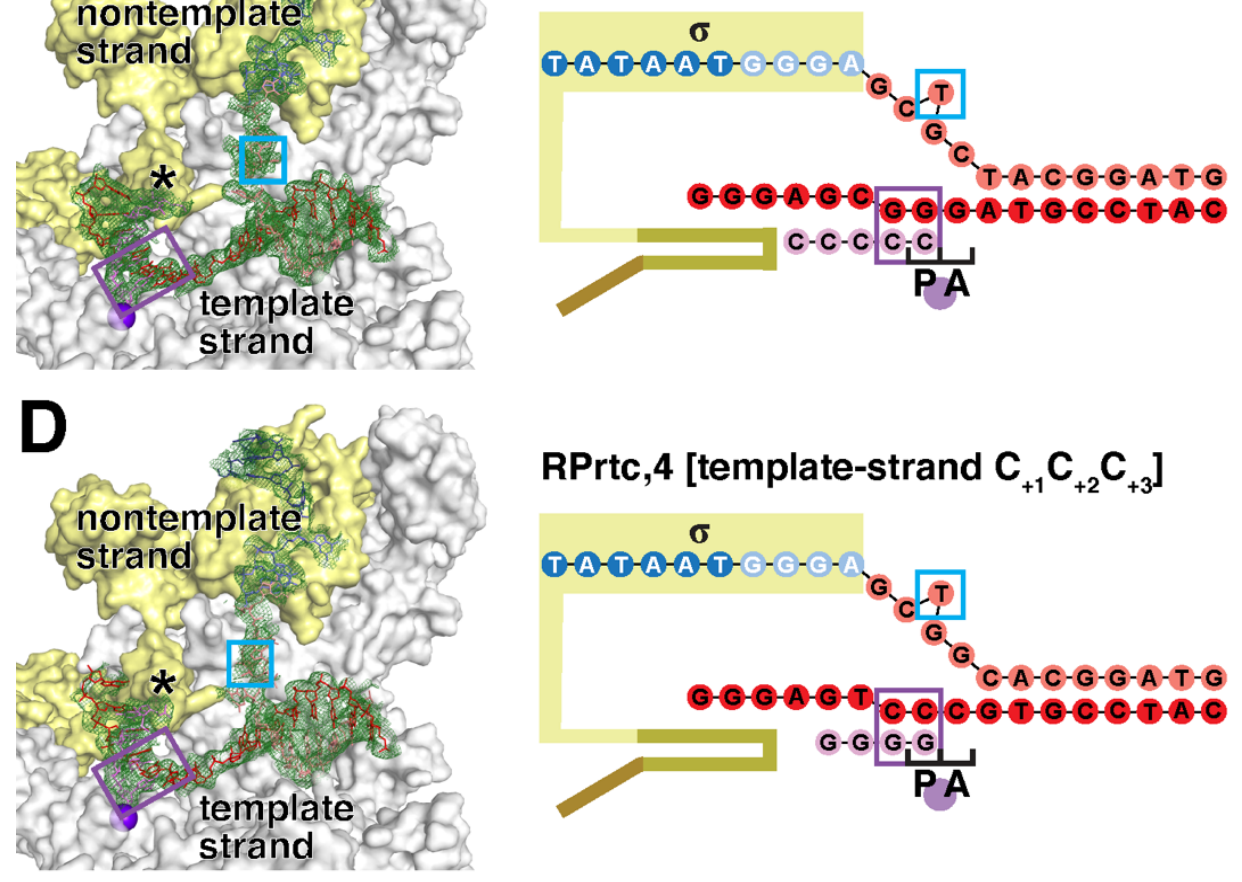

Figure 1 


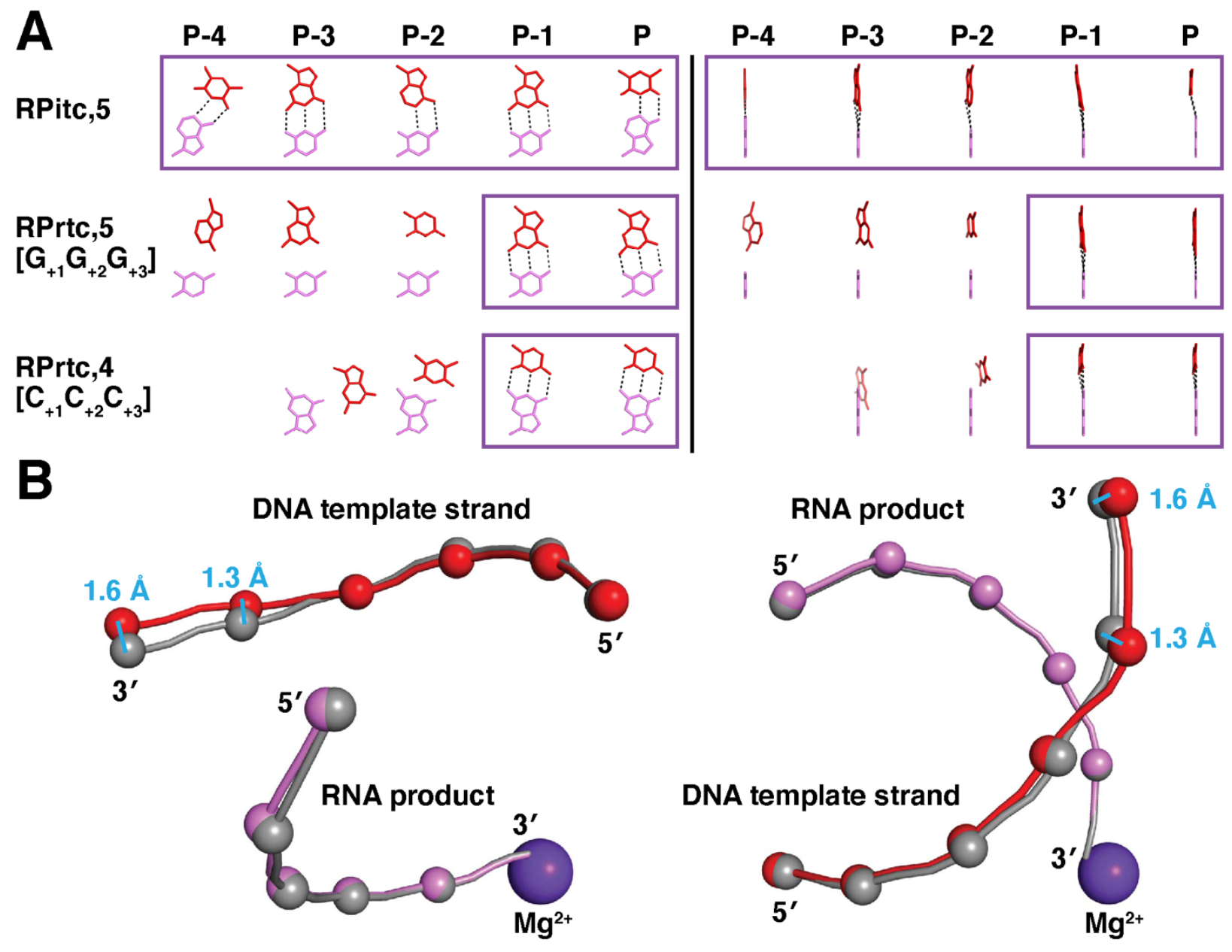

Figure 2 


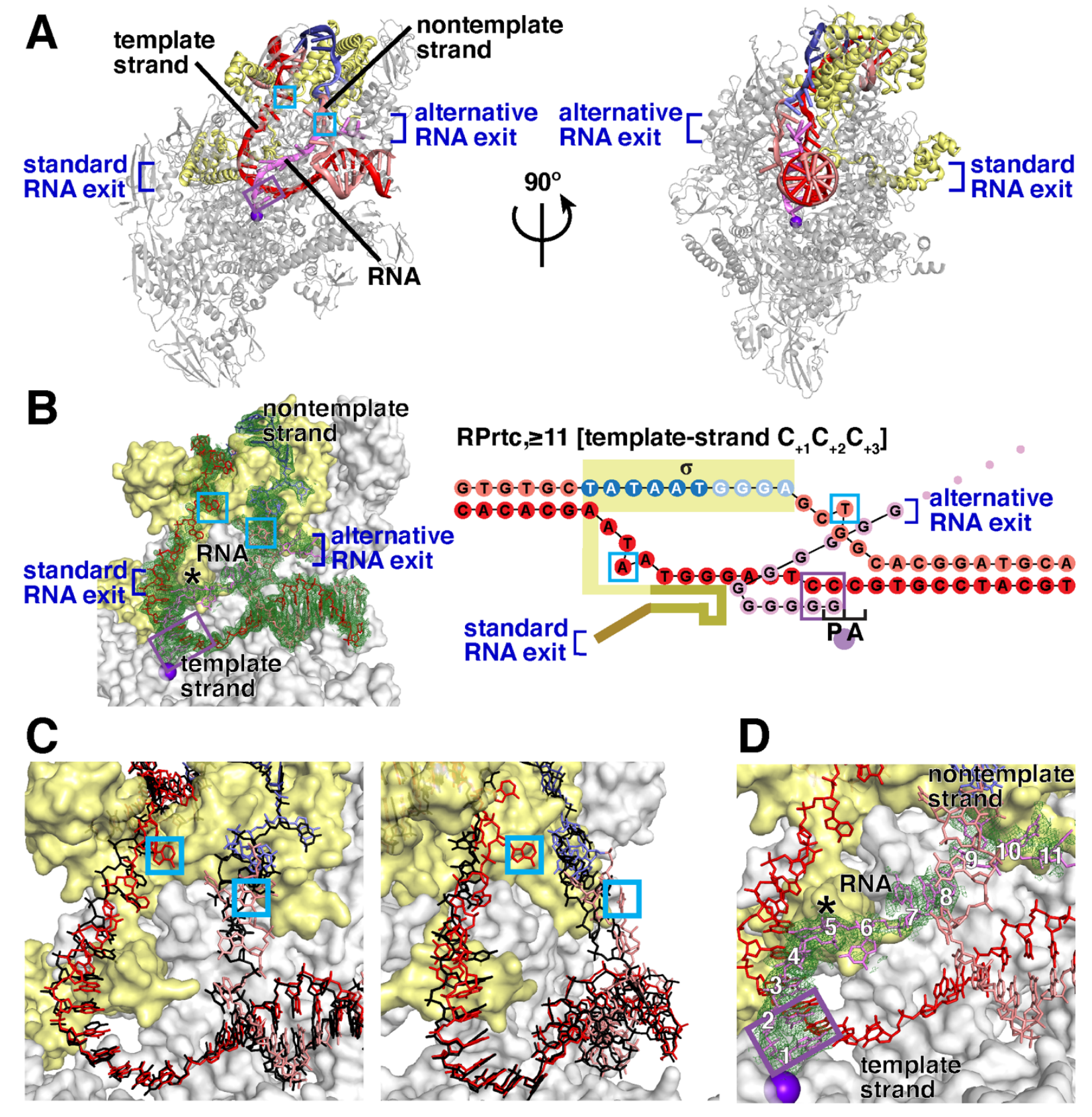

Figure 3 


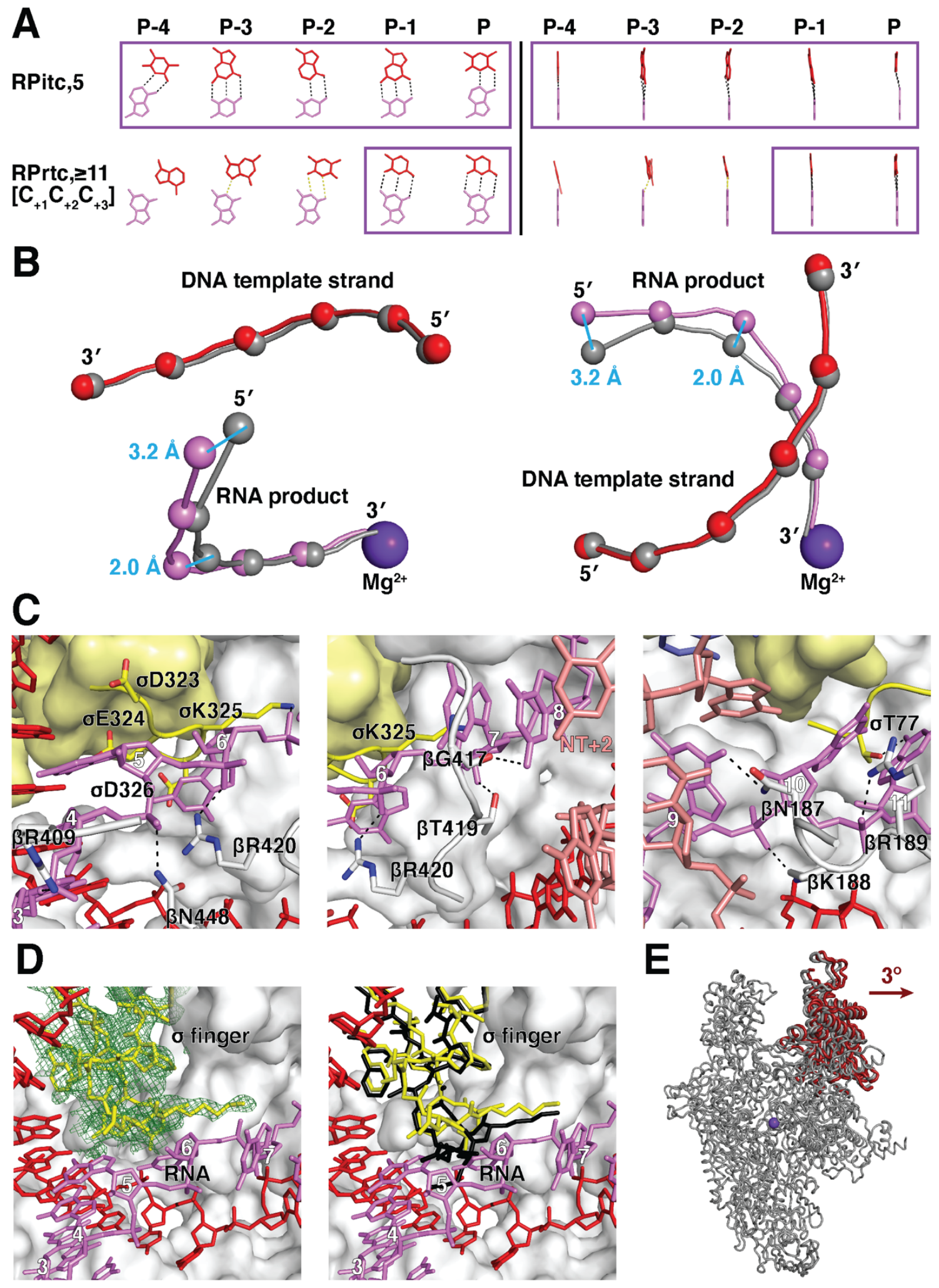

Figure 4 


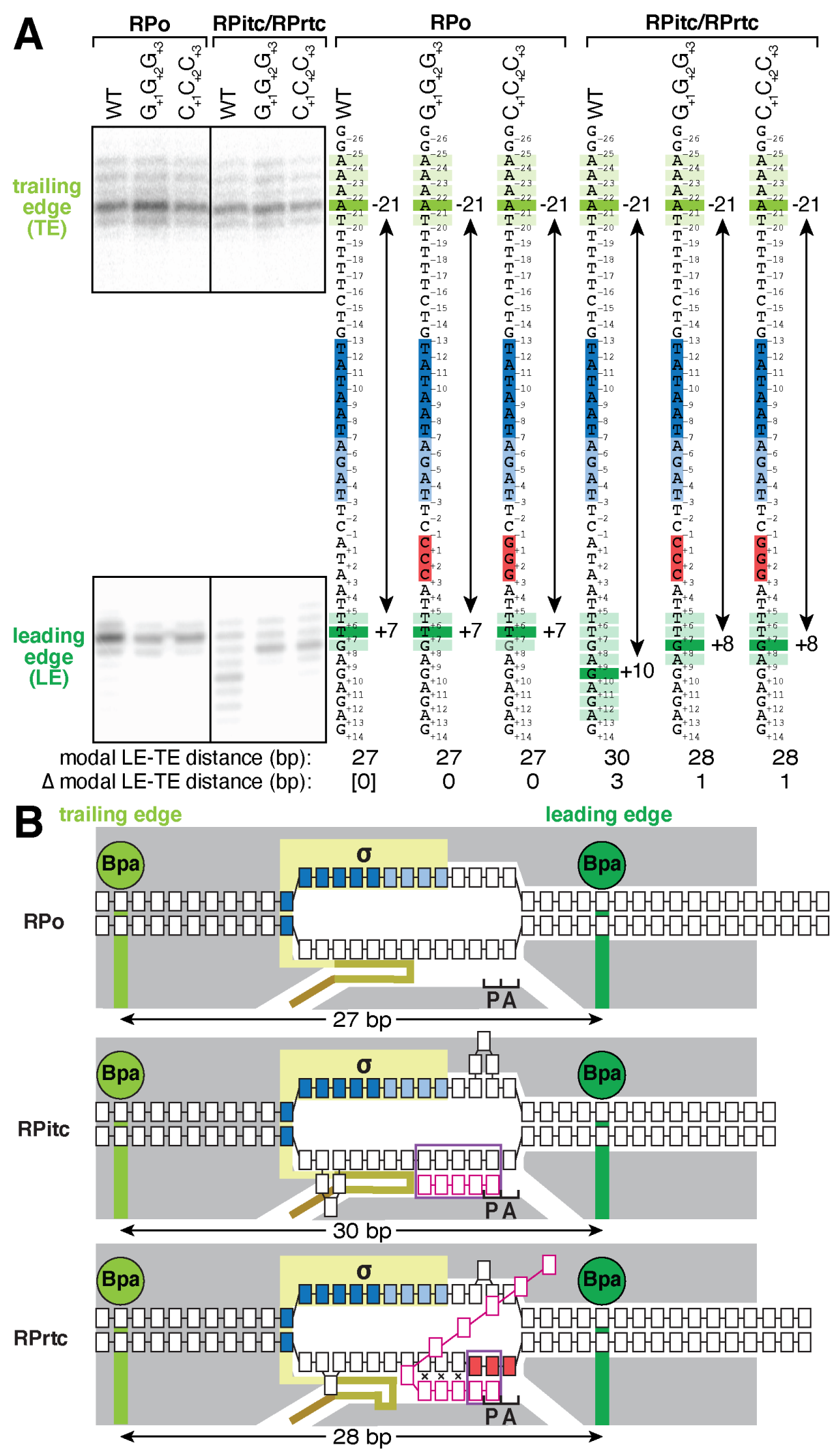

Figure 5 


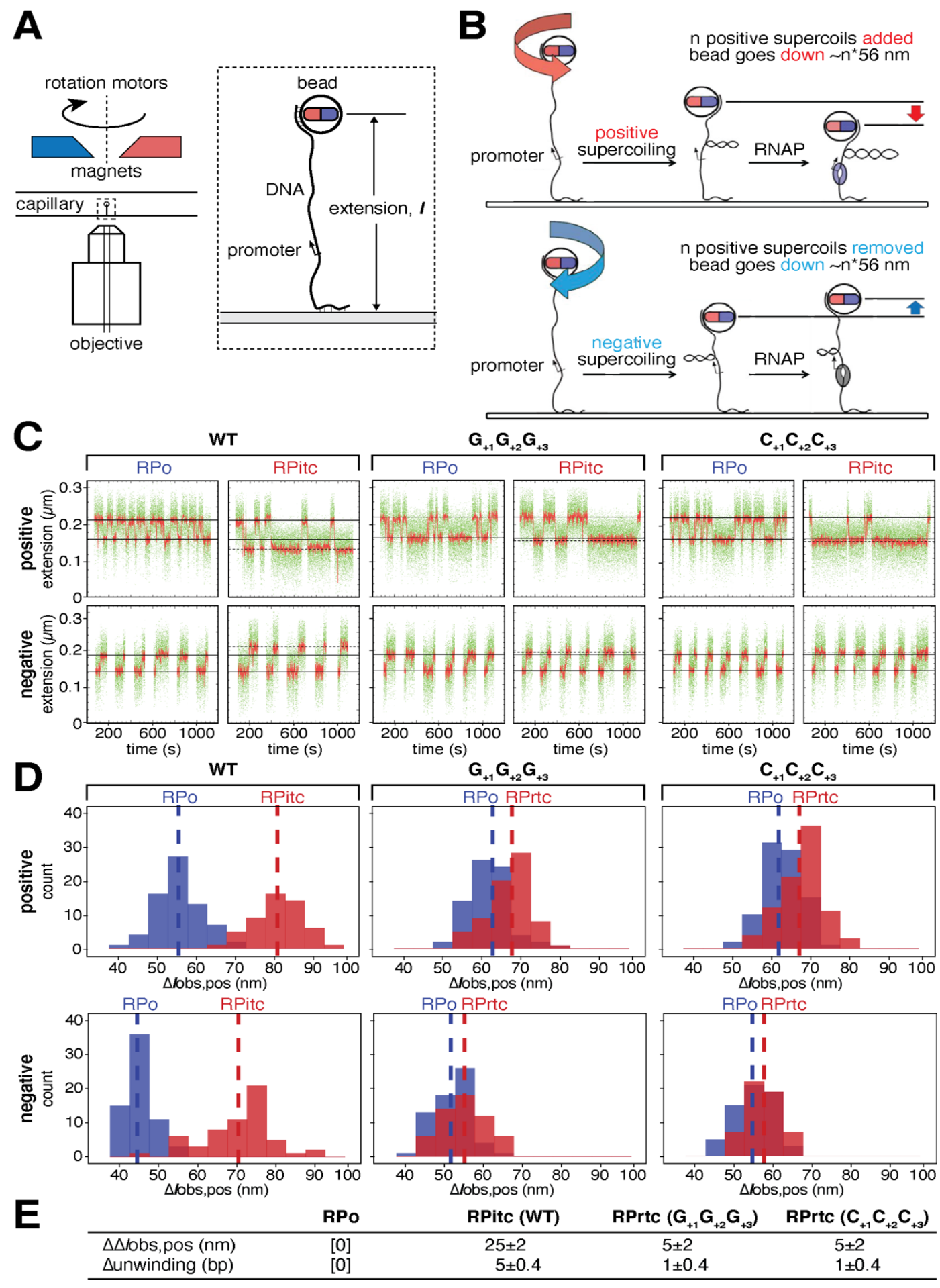

\section{Figure 6}




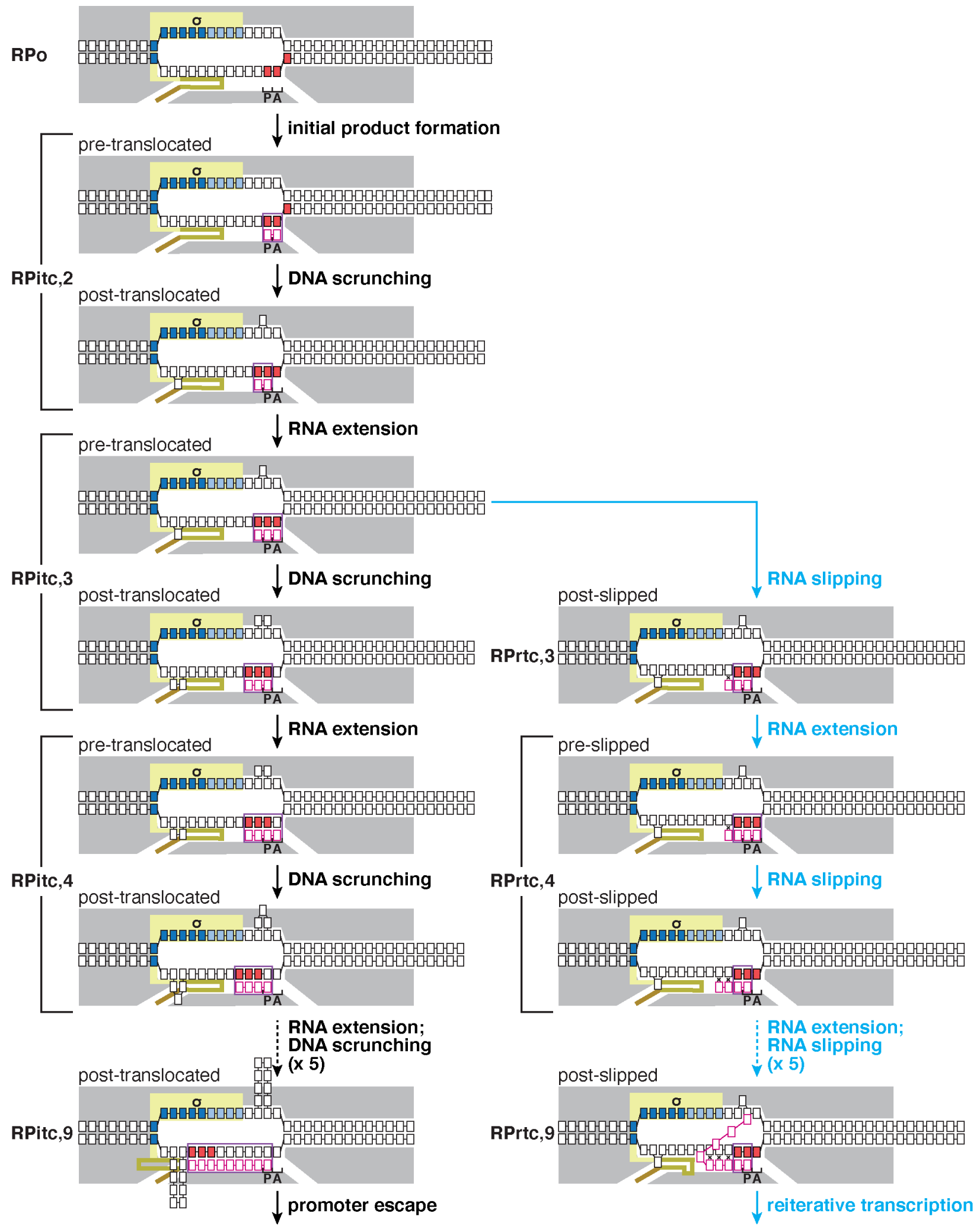

Figure 7 


\section{Supplementary Materials:}

\section{Materials and Methods}

\section{Proteins}

T. thermophilus RNAP core enzyme was prepared from T. thermophilus strain H8 (DSM 579; German Collection of Microorganisms and Cell Cultures $\mathrm{GmbH})$, using cell lysis, polyethylenimine precipitation, ammonium sulfate precipitation, and ion-exchange chromatography on SP Sepharose FF (GE Healthcare Life Sciences, Inc.), Mono Q (GE Healthcare Life Sciences, Inc.), and Mono S HR (GE Healthcare Life Sciences, Inc.), as in (Maffioli et al., 2017; Zhang et al., 2012).

T. thermophilus $\sigma^{\mathrm{A}}$ was prepared by expression of a gene for N-terminally hexahistidine-tagged T. thermophilus $\sigma^{\mathrm{A}}$ in E. coli, followed by cell lysis, immobilized-metal-ion affinity chromatography on Ni-NTA agarose (Qiagen, Inc.), and anion-exchange chromatography on Mono Q (GE Healthcare Life Sciences, Inc.), as in (Zhang et al., 2012).

T. thermophilus RNAP $\sigma^{\mathrm{A}}$ holoenzyme was prepared by incubating $15 \mu \mathrm{M}$ T. thermophilus RNAP core enzyme and $60 \mu \mathrm{M}$ T. thermophilus $\sigma^{\mathrm{A}}$ in $2 \mathrm{ml} 20 \mathrm{mM}$ Tris- $\mathrm{HCl}(\mathrm{pH} 7.9), 150 \mathrm{mM} \mathrm{NaCl}$, and $1 \%$ glycerol for $12 \mathrm{~h}$ at $4^{\circ} \mathrm{C}$, followed by size-exclusion chromatography on Superdex 200 (GE Healthcare Life Sciences, Inc.), as in (Zhang et al., 2012).

Bpa-containing E. coli RNAP core enzyme derivatives RNAP- $\beta^{\prime 21148 B p a}$ and RNAP- $\beta^{\text {' }}{ }^{\text {T48Bpa }}$ were prepared from E. coli strain NiCo21(DE3) (New England Biolabs, Inc.) transformed with plasmid pEVOL-pBpF (Chin et al., 2002) and either plasmid pIA900-RNAP- $\beta^{\prime \text { R1148Bpa }}$ (Winkelman et al., 2015) or plasmid pIA900-RNAP- $\beta^{\prime \text { T48Bpa }}$ (Winkelman et al., 2015), using procedures as in (Winkelman et al., 2015). E. coli RNAP core enzyme without Bpa was prepared from E. coli strain NiCo21(DE3) (New England Biolabs, Inc.) transformed with plasmid pIA900 (Svetlov and Artsimovitch, 2015), using procedures as in (Winkelman et al., 2015). 
E. coli $\sigma^{70}$ was prepared from E. coli strain NiCo21(DE3) transformed with plasmid $\mathrm{p \sigma}^{70}-\mathrm{His}$ (gift of J. Roberts; Marr and Roberts, 1997), using procedures as in (Marr and Roberts, 1997).

E. coli RNAP $\sigma^{70}$ holoenzyme was prepared by incubating $1 \mu \mathrm{M}$ E. coli RNAP core enzyme and $5 \mu \mathrm{M}$ E. coli $\sigma^{70}$ in $10 \mathrm{mM}$ Tris-Cl (pH 8.0), $100 \mathrm{mM} \mathrm{KCl}, 10 \mathrm{mM} \mathrm{MgCl} 2,0.1 \mathrm{mM}$ EDTA, $1 \mathrm{mM}$ DTT, and $50 \%$ glycerol for $30 \mathrm{~min}$ at $25^{\circ} \mathrm{C}$.

\section{Oligodeoxyribonucleotides}

Oligodeoxyribonucleotides (Table S2) were purchased from IDT, Inc.

\section{Nucleic-acid scaffolds for structure determination}

Nucleic-acid scaffolds for crystallization were prepared by incubating $20 \mathrm{nmol}$ nontemplate-strand oligodeoxyribonucleotide and $22 \mathrm{nmol}$ template-strand oligodeoxyribonucleotide in $50 \mu \mathrm{l} 5 \mathrm{mM}$ Tris- $\mathrm{HCl}(\mathrm{pH} 7.9), 200 \mathrm{mM} \mathrm{NaCl}$, and $10 \mathrm{mM} \mathrm{MgCl}_{2}$ for $5 \mathrm{~min}$ at $95^{\circ} \mathrm{C}$, followed by cooling to $25^{\circ} \mathrm{C}$ in $2^{\circ} \mathrm{C}$ steps with 1 min per step using a thermal cycler (Applied Biosystems, Inc.), and were stored at $-80^{\circ} \mathrm{C}$.

Crystal-structure determination: crystal growth and in crystallo RNA synthesis

RPo was prepared by mixing $20 \mu 118 \mu \mathrm{M}$ T. thermophilus RNAP $\sigma^{\mathrm{A}}$ holoenzyme in $20 \mathrm{mM}$ Tris- $\mathrm{HCl}$ (pH 7.9), $100 \mathrm{mM} \mathrm{NaCl}$, and $1 \%$ glycerol with $1.1 \mu \mathrm{l} 0.4 \mathrm{mM}$ nucleic-acid scaffold in $5 \mathrm{mM}$ Tris- $\mathrm{HCl}$ (pH 7.9), $200 \mathrm{mM} \mathrm{NaCl}$, and $10 \mathrm{mM} \mathrm{MgCl}_{2}$, and incubating $1 \mathrm{~h}$ at $25^{\circ} \mathrm{C}$.

Crystallization was performed essentially as in (Zhang et al., 2012). Crystallization drops containing $1 \mu \mathrm{l} 20 \mu \mathrm{M}$ RPo in $20 \mathrm{mM}$ Tris- $\mathrm{HCl}$ (pH 7.9), $100 \mathrm{mM} \mathrm{NaCl}, 1 \%$ glycerol and $1 \mu 1$ reservoir solution [0.1 M Tris- $\mathrm{HCl}(\mathrm{pH} 8.4), 180 \mathrm{mM} \mathrm{KCl}, 50 \mathrm{mM} \mathrm{MgCl}_{2}$, and 9\% (m/v) PEG 4000] were equilibrated with $400 \mu \mathrm{l}$ reservoir solution in sealed hanging-drop plates. Crystals were grown 5 days at $22^{\circ} \mathrm{C}$. Micro-seeding was performed as needed using the same reservoir solution. 
In crystallo RNA synthesis was performed by adding $0.2 \mu 110 \mathrm{mM}$ each NTP (ATP, UTP, and CTP for RPitc,5; CTP for RPrtc, $5\left[\mathrm{G}_{+1} \mathrm{G}_{+2} \mathrm{G}_{+3}\right]$; GTP for RPrtc, $\left.4\left[\mathrm{C}_{+1} \mathrm{C}_{+2} \mathrm{C}_{+3}\right]\right)$ in reservoir solution directly into crystallization drops at $22^{\circ} \mathrm{C}$, incubating $2 \mathrm{~min}$ at $22^{\circ} \mathrm{C}$, transferring crystals to $2 \mu$ reservoir solution containing $18 \%(\mathrm{v} / \mathrm{v})(2 \mathrm{R}, 3 \mathrm{R})-(-)-2,3$-butanediol (Sigma-Aldrich, Inc.) at $22^{\circ} \mathrm{C}$, and flash-cooling in liquid nitrogen.

Crystal-structure determination: data collection and data reduction

Diffraction data were collected from cryo-cooled crystals at Stanford Synchrotron Radiation Lightsource (SSRL) beamline 9-2 (RPrtc,5 $\left[\mathrm{G}_{+1} \mathrm{G}_{+2} \mathrm{G}_{+3}\right]$ and RPrtc, $4\left[\mathrm{C}_{+1} \mathrm{C}_{+2} \mathrm{C}_{+3}\right]$; Table S2) and at Argonne Photon Source (APS) beamline 19-ID (RPitc,5; Table S2). Data were processed using HKL3000 (Minor et al., 2006). Structures were solved by molecular replacement using the crystal structure of $T$. thermophilus RPo (PDB 4G7H; Zhang et al., 2012) as search model. Iterative cycles of reciprocal refinement using Phenix (Liebschner et al., 2019) and real-space model building using Coot (Emsley et al., 2010) were performed. Improvement of the coordinate model resulted in improvement of phasing, and electron density maps for nucleic acids, which were not included in models at this stage of model building and refinement, improved over successive cycles. Nucleic acids then were built into the model and refined in stepwise fashion. The RPitc, 5 model refined to $\mathrm{R}_{\mathrm{work}}=0.23$ and $\mathrm{R}_{\text {free }}=0.27$, the RPrtc, 5 $\left[\mathrm{G}_{+1} \mathrm{G}_{+2} \mathrm{G}_{+3}\right]$ model refined to $\mathrm{R}_{\mathrm{work}}=0.24$ and $\mathrm{R}_{\text {free }}=0.29$, and the $\mathrm{RPrtc}, 4\left[\mathrm{C}_{+1} \mathrm{C}_{+2} \mathrm{C}_{+3}\right]$ refined to $\mathrm{R}_{\mathrm{work}}=$ 0.26 and $\mathrm{R}_{\mathrm{free}}=0.28$. The final atomic models and structure factors were deposited in the Protein Data Bank (PDB) with accession codes RPitc,5 (7MLB), RPrtc,5 $\left[\mathrm{G}_{+1} \mathrm{G}_{+2} \mathrm{G}_{+3}\right](7 \mathrm{MLI})$, and RPrtc, $4\left[\mathrm{C}_{+1} \mathrm{C}_{+2} \mathrm{C}_{+3}\right]$ (7MLJ; Table S2).

Cryo-EM structure determination: sample preparation

QUANTIFOIL R 2/1 Cu 300 mesh (Quantifoil) grids were glow-discharged and graphene-oxide-coated as in (Pantelic et al., 2010; Thomas et al., 2016). Grids were glow-discharged at 
$25 \mathrm{~mA}$ and $0.27 \mathrm{mBar}$ for $60 \mathrm{~s}$ using a glow-discharge cleaning system (PELCO easiGlow; Ted Pella), $3 \mu 10.2 \mathrm{mg} / \mathrm{ml}$ graphene oxide suspension in water (Sigma) was applied to each grid, and, after $90 \mathrm{~s}$ at $25^{\circ} \mathrm{C}$, and were blotted using \#595 filter paper (Ted Pella) for $1 \mathrm{~s}$ at $25^{\circ} \mathrm{C}$, washed with $3 \times 3 \mu$ water (twice on graphene-oxide side and once on opposite side), and stored under vacuum at $25^{\circ} \mathrm{C}$ until use.

RPo was prepared by mixing $20 \mu \mathrm{l} 18 \mu \mathrm{M}$ T. thermophilus RNAP $\sigma^{\mathrm{A}}$ holoenzyme in $20 \mathrm{mM}$ Tris $\mathrm{HCl}$ (pH 7.9), $100 \mathrm{mM} \mathrm{NaCl}$, and $5 \mathrm{mM} \mathrm{MgCl}_{2}$ with $1.1 \mu \mathrm{l} 0.4 \mathrm{mM}$ nucleic-acid scaffold in $5 \mathrm{mM}$ Tris $\mathrm{HCl}$ (pH 7.9), $200 \mathrm{mM} \mathrm{NaCl}$, and $10 \mathrm{mM} \mathrm{MgCl}_{2}$ and incubating $1 \mathrm{~h}$ at $25^{\circ} \mathrm{C}$. Samples of RPrtc were prepared by diluting $2 \mu \mathrm{RPo}$ with $16 \mu \mathrm{l} 20 \mathrm{mM}$ Tris $\mathrm{HCl}\left(\mathrm{pH}\right.$ 7.9), $100 \mathrm{mM} \mathrm{NaCl}$, and $5 \mathrm{mM} \mathrm{MgCl}_{2}$ at $25^{\circ} \mathrm{C}$, adding $2 \mathrm{ul} 10 \mathrm{mM} \mathrm{GTP}$, and incubating $20 \mathrm{~min}$ at $25^{\circ} \mathrm{C}$. Aliquots of samples of RPrtc $(3 \mu \mathrm{l})$ were applied to graphene-oxide-coated grids mounted on a Vitrobot Mark IV autoplunger (FEI/ThermoFisher) at $4{ }^{\circ} \mathrm{C}$ and $95 \%$ relative humidity, and grids were incubated $30 \mathrm{~s}$, blotted with \#595 filter paper (Ted Pella) for $7 \mathrm{~s}$, flash-frozen by plunging in liquid ethane cooled with liquid nitrogen, and stored in liquid nitrogen.

\section{Cryo-EM structure determination: data collection and data reduction}

Cryo-EM data were collected at the Rutgers University Cryo-EM and Nanoimaging Facility, using a $200 \mathrm{kV}$ Talos Arctica (FEI/ThermoFisher) electron microscope equipped with a GIF Quantum K2 direct electron detector (Gatan). Data were collected using Serial EM (Mastronarde, 2018), a nominal magnification of $130,000 \mathrm{x}$, a calibrated pixel size of $1.038 \AA /$ pixel, and a dose rate of 4.97 electrons/pixel/s. Movies were recorded at $200 \mathrm{~ms} /$ frame for $6 \mathrm{~s}$ (30 frames). Defocus range was varied between $-1.2 \mu \mathrm{m}$ and $-2.8 \mu \mathrm{m}$. A total of 3,424 micrographs were recorded from one grid over two days. Micrographs were gain-normalized and defect-corrected.

Data were processed as summarized in Figure S2A. Data processing was performed using a Tensor TS4 Linux GPU workstation with four GTX 1080 Ti graphic cards (NVIDIA). Dose-weighting motion correction $(5 \times 5$ tiles; b-factor $=150)$ was performed using Motioncor2 (Zheng et al., 2017). 
Contrast-transfer-function (CTF) estimation was performed using CTFFIND-4.1 (Rohou and Grigorieff, 2015). Subsequent image processing was performed using Relion 3.1 (Zivanov et al., 2018). 2,143,284 Particles were picked using Relion Auto-picking with a 2D class reference. Particles were extracted into 256 pixel x 256 pixel boxes and were subjected to rounds of reference-free $2 \mathrm{D}$ classification, 3D classification, and removal of poorly populated classes, yielding a selected set of 663,667 particles. The selected set was used in 3D auto-refinement, CTF refinement (addressing higher-order aberrations, anisotropic magnification, and per-particle defocus), Bayesian polishing, and post-processing. A total of 339,426 particles was selected after further classification, and a density map at 3.0 A overall resolution was obtained, as determined from gold-standard Fourier shell correlation (FSC; Figure S2D-E). The initial atomic model was built by manual rigid-body fitting of RNAP $\beta$ ', RNAP $\beta$, RNAP $\alpha^{\mathrm{I}}$, RNAP $\alpha^{\text {II }}$, RNAP $\omega$, and $\sigma$ segments from the crystal structure of $T$. thermophilus RPo (PDB 4G7H; Zhang et al., 2012) into the cryo-EM density map using Coot (Emsley et al., 2010), followed by manual fitting of DNA and RNA into the cryo-EM density map using Coot. For RNAP $\beta^{\prime}$ residues 219-337 (part of the T. thermophilus $\beta^{\prime}$ non-conserved region; Chlenov et al., 2005), density was absent, suggesting high segmental flexibility; this segment was not fitted. The complex was real-space-refined using secondary structure and nucleic acid restraints in PHENIX (Liebschner et al., 2019). The final atomic model, with map-to-model correlation of 0.70, was deposited in the Electron Microscopy Data Bank (EMDB) and the PDB with accession codes EMD-24424 and 7RDQ, respectively.

\section{DNA templates for in vitro transcription and crosslinking assays}

Linear DNA templates used for in vitro transcription (Figure S1B) and in vitro photo-crosslinking assays (Figure 5) contain sequences from positions -72 to +71 of N25 or positions -72 to +71 of N25 promoter containing template-strand $\mathrm{G}_{+1} \mathrm{G}_{+2} \mathrm{G}_{+3}$ and $\mathrm{C}_{+1} \mathrm{C}_{+2} \mathrm{C}_{+3}$ homopolymeric sequences (N25 $\left[\mathrm{G}_{+1} \mathrm{G}_{+2} \mathrm{G}_{+3}\right]$ and $\mathrm{N} 25\left[\mathrm{C}_{+1} \mathrm{C}_{+2} \mathrm{C}_{+3}\right]$, respectively). Templates were generated by PCR in reactions containing 1 X Phusion HF Master Mix (Thermo Fisher Scientific, Inc.), $0.8 \mu \mathrm{M}$ primer N25B, $0.8 \mu \mathrm{M}$ 
primer N25T, and $\sim 1$ pg of oligos JW173 (N25), JW169 (N25 $\left.\left[\mathrm{G}_{+1} \mathrm{G}_{+2} \mathrm{G}_{+3}\right]\right)$, or JW170 (N25

$\left.\left[\mathrm{C}_{+1} \mathrm{C}_{+2} \mathrm{C}_{+3}\right]\right)$. Reaction products were purified using a PCR purification kit (Qiagen, Inc.).

Nontemplate-strand sequence from positions -72 to +71 of $\mathrm{N} 25$ :

5'-GAGAGAGGTACCTCGAGGGAAATCATAAAAAATTTATTTGCTTTCAGGAAAATTTTTCTGT

ATAATAGATTCATAATTTGAGAGAGGAGTTTAAATATGGCTGGTTCTCGCGAGAATTCCGAA

TAGCCATCCCAATCGAACAG-3'

Nontemplate-strand sequence from positions -72 to +71 of $N 25\left[\mathrm{G}_{+1} \mathrm{G}_{+2} \mathrm{G}_{+3}\right]$ :

5'-GAGAGAGGTACCTCGAGGGAAATCATAAAAAATTTATTTGCTTTCAGGAAAATTTTTCTGT

ATAATAGATTCCCCATTTGAGAGAGGAGTTTAAATATGGCTGGTTCTCGCGAGAATTCCGAA

TAGCCATCCCAATCGAACAG-3'

Nontemplate-strand sequence from positions -72 to +71 of $\mathrm{N} 25\left[\mathrm{C}_{+1} \mathrm{C}_{+2} \mathrm{C}_{+3}\right]$ :

5'-GAGAGAGGTACCTCGAGGGAAATCATAAAAAATTTATTTGCTTTCAGGAAAATTTTTCTGT

ATAATAGATTCGGGATTTGAGAGAGGAGTTTAAATATGGCTGGTTCTCGCGAGAATTCCGAA

TAGCCATCCCAATCGAACAG-3'

In vitro transcription

In vitro transcription experiments in Figure S1A were performed using reaction mixtures $(40 \mu \mathrm{l})$ containing $17 \mu \mathrm{M}$ T. thermophilus RNAP $\sigma^{\mathrm{A}}$ holoenzyme or E. coli RNAP $\sigma^{70}$ holoenzyme and $21 \mu \mathrm{M}$ nucleic-acid scaffold (see "Nucleic-acid scaffolds for structure determination") in $20 \mathrm{mM}$ Tris-HCl (pH 7.9), $100 \mathrm{mM} \mathrm{NaCl}$, and $5 \mathrm{mM} \mathrm{MgCl}$. For reactions with scaffold 1 (sequence in Figure $\mathrm{S} 1 \mathrm{~A}$ ), $1 \mathrm{mM}$ ATP and $1 \mathrm{mM}$ UTP, along with $1 \mu 1200 \mathrm{~Bq} / \mathrm{fmol}\left[\mathrm{a}^{32} \mathrm{P}\right]$-UTP (PerkinElmer, Inc.), were added to initiate RNA synthesis. For reactions with scaffold 2 (sequence in Figure S1A), 1 mM CTP, along with $1 \mu 1200$ $\mathrm{Bq} / \mathrm{fmol}\left[\mathrm{a}^{32} \mathrm{P}\right]-\mathrm{CTP}$ (PerkinElmer, Inc.), was added to initiate RNA synthesis. For reactions with scaffold 3 and scaffold 4 (sequences in Figure S1A), 1 mM GTP, along with $1 \mu 1200 \mathrm{~Bq} / \mathrm{fmol}\left[\mathrm{a}^{32} \mathrm{P}\right]-\mathrm{GTP}$

(PerkinElmer, Inc.), was added to initiate RNA synthesis. After 3 min at $25^{\circ} \mathrm{C}$ (for $T$. thermophilus RNAP 
$\sigma^{\mathrm{A}}$ holoenzyme) or $0.5 \mathrm{~min}$ at $25^{\circ} \mathrm{C}$ (for $E$. coli $\mathrm{RNAP} \sigma^{70}$ holoenzyme), reactions were terminated by addition of $100 \mu 110 \mathrm{mM}$ EDTA (pH 8.0) and $1 \mathrm{mg} / \mathrm{ml}$ glycogen.

In vitro transcription experiments in Figure $\mathrm{S} 1 \mathrm{~B}$ were performed using reaction mixtures $(10 \mu \mathrm{l})$ containing $40 \mathrm{nM}$ RNAP holoenzyme derivative and $4 \mathrm{nM}$ promoter derivative (see "DNA templates for photocrosslinking assays") in $10 \mathrm{mM}$ Tris- $\mathrm{HCl}$ (pH 8.0), $100 \mathrm{mM} \mathrm{KCl}, 10 \mathrm{mM} \mathrm{MgCl}$, and $0.1 \mathrm{mg} / \mathrm{ml}$ bovine serum albumin. For reactions with promoter derivative N25 WT (sequence in Figure S1B), 200 $\mu \mathrm{M}$ ATP and $200 \mu \mathrm{M}$ UTP, along with $1 \mu 1200 \mathrm{~Bq} / \mathrm{fmol}\left[\mathrm{a}^{32} \mathrm{P}\right]-\mathrm{UTP}$ (PerkinElmer, Inc.), were added to initiate RNA synthesis. For reactions with promoter derivative $N 25\left[\mathrm{G}_{+1} \mathrm{G}_{+2} \mathrm{G}_{+3}\right]$ (sequence in Figure S1B), $200 \mu \mathrm{M}$ CTP, along with $1 \mu 1200 \mathrm{~Bq} / \mathrm{fmol}$ [a $\mathrm{a}^{32} \mathrm{P}$ ]-CTP (PerkinElmer, Inc.), was added to initiate RNA synthesis. For reactions with promoter derivative N25 [ $\left.\mathrm{C}_{+1} \mathrm{C}_{+2} \mathrm{C}_{+3}\right]$ (sequence in Figure S1B), 200 $\mu$ M GTP, along with $1 \mu 1200 \mathrm{~Bq} / \mathrm{fmol}\left[\mathrm{a}^{32} \mathrm{P}\right]-\mathrm{GTP}$ (PerkinElmer, Inc.), was added to initiate RNA synthesis. After $20 \mathrm{~min}$ at $37^{\circ} \mathrm{C}$, reactions were terminated by addition of $100 \mu 110 \mathrm{mM}$ EDTA (pH 8.0) and $1 \mathrm{mg} / \mathrm{ml}$ glycogen.

For both experiments in Figure S1A and experiments in Fiogire S1B, reaction mixtures were extracted with acidic phenol:chloroform (Ambion, Inc.), and RNA products were recovered by ethanol precipitation and re-suspended in $6.5 \mu 1$ water. Samples were diluted 2-fold in urea loading dye (1 X TBE, $8 \mathrm{M}$ urea, $0.025 \%$ xylene cyanol, and $0.025 \%$ bromophenol blue), and samples were analyzed by electrophoresis on 20\%, 8 M urea, 1 X TBE polyacrylamide gels (UreaGel System; National Diagnostics, Inc.), followed by storage-phosphor imaging (Typhoon 9400 variable-mode imager; GE Healthcare Life Sciences, Inc.). Sizes of RNA products were estimated by comparison to radiolabeled Decade Marker (ThermoFisher Scientific, Inc.).

Determination of RNAP active-center A-site positions by protein-DNA photo-crosslinking in vitro In vitro photo-crosslinking and crosslink mapping experiments were done using procedures described in (Yu et al., 2017). For the experiments in Figure 5, $50 \mu 1$ reactions containing $100 \mathrm{nM}$ RNAP 
holoenzyme, $10 \mathrm{nM}$ template, $1 \mathrm{mM} \mathrm{CpA}$ dinucleotide (for N25 RPo samples), 1mM CpC dinucleotide (for $\mathrm{N} 25\left[\mathrm{G}_{+1} \mathrm{G}_{+2} \mathrm{G}_{+3}\right]$ RPo samples), or CpG dinucleotide (for $\mathrm{N} 25\left[\mathrm{C}_{+1} \mathrm{C}_{+2} \mathrm{C}_{+3}\right]$ RPo samples) and 200 $\mu \mathrm{M}$ ATP and UTP (for N25 RPitc samples), $200 \mu \mathrm{M}$ CTP (for $\mathrm{N} 25\left[\mathrm{G}_{+1} \mathrm{G}_{+2} \mathrm{G}_{+3}\right]$ RPrtc samples), or 200 $\mu \mathrm{M}$ GTP (for $\mathrm{N} 25\left[\mathrm{C}_{+1} \mathrm{C}_{+2} \mathrm{C}_{+3}\right]$ RPrtc samples) and $1 \mathrm{X}$ RB [10 mM Tris-Cl (pH 8.0), $70 \mathrm{mM} \mathrm{NaCl}, 10$ $\mathrm{mM} \mathrm{MgCl}$, and $0.1 \mathrm{mg} / \mathrm{ml} \mathrm{BSA}$ ] were incubated for $2 \mathrm{~min}$ at $25^{\circ} \mathrm{C}$, and $\mathrm{UV}$ irradiated for $5 \mathrm{~min}$ at $25^{\circ} \mathrm{C}$ in a Rayonet RPR-100 photochemical reactor equipped with 16 × $350 \mathrm{~nm}$ tubes (Southern New England Ultraviolet, Inc.).

To denature RNAP-DNA complexes, reactions were mixed with $15 \mu 15 \mathrm{M} \mathrm{NaCl}$ and $6 \mu 100$ $\mu \mathrm{g} / \mathrm{ml}$ heparin, incubated for $5 \mathrm{~min}$ at $95^{\circ} \mathrm{C}$, and cooled to $4^{\circ} \mathrm{C}$. Crosslinked RNAP-DNA complexes were isolated by adding $20 \mu \mathrm{l}$ MagneHis Ni-particles (Promega, Inc.) equilibrated and suspended in $10 \mathrm{mM}$ Tris-Cl (pH 8.0), 1.2 M NaCl, $10 \mathrm{mM} \mathrm{MgCl} 2,10 \mu \mathrm{g} / \mathrm{ml}$ heparin, and $0.1 \mathrm{mg} / \mathrm{ml} \mathrm{BSA}$; MagneHis Ni-particles were collected using a magnetic microfuge tube rack; particles were washed with $50 \mu 110$ $\mathrm{mM}$ Tris- $\mathrm{Cl}$ (pH 8.0), 1.2 M NaCl, $10 \mathrm{mM} \mathrm{MgCl} 2,10 \mu \mathrm{g} / \mathrm{ml}$ heparin, and $0.1 \mathrm{mg} / \mathrm{ml} \mathrm{BSA}$, washed twice with $50 \mu 11$ X Taq DNA polymerase buffer (New England Biolabs, Inc.), and particles (which contained bound RNAP-DNA complexes) were resuspended in $10 \mu 11$ X Taq DNA polymerase buffer. For leading-edge crosslink mapping, primer extension reactions $(12.5 \mu 1)$ were performed by combining $2 \mu 1$ of the recovered RNAP-DNA complexes, $1 \mu 1$ of $1 \mu \mathrm{M}^{32} \mathrm{P}-5$ '-end-labeled primer N25B [200 Bq/fmol; prepared using $\left[\gamma^{32} \mathrm{P}\right]$-ATP (PerkinElmer, Inc.)] and T4 polynucleotide kinase (New England Biolabs, Inc.) as described in (Sambrook and Russell, 2006)], $1.25 \mu 110 \mathrm{X}$ dNTPs (2.5 mM dATP, $2.5 \mathrm{mM} \mathrm{dCTP,}$ 2.5 mM dGTP, 2.5 mM TTP; GE Healthcare Life Sciences, Inc.), $0.5 \mu 15 \mathrm{U} / \mu 1$ Taq DNA polymerase (New England Biolabs, Inc.), $5 \mu 15 \mathrm{M}$ betaine, $0.625 \mu 1$ 100\% dimethyl sulfoxide, and $1.25 \mu 110 \mathrm{X} \mathrm{Taq}$ DNA polymerase buffer; 40 cycles of $30 \mathrm{~s}$ at $95^{\circ} \mathrm{C}, 30 \mathrm{~s}$ at $53^{\circ} \mathrm{C}$, and $30 \mathrm{~s}$ at $72^{\circ} \mathrm{C}$. For trailing-edge crosslink mapping, primer extension reactions $(12.5 \mu 1)$ were performed by combining $2 \mu 1$ of the recovered RNAP-DNA complexes, $1 \mu \mathrm{l}$ of $1 \mu \mathrm{M}{ }^{32} \mathrm{P}-5$ '-end-labeled primer N25T [200 Bq/fmol; prepared using $\left[\gamma^{32} \mathrm{P}\right]$-ATP (PerkinElmer, Inc.)] and T4 polynucleotide kinase (New England Biolabs, Inc.) as 
described in (Sambrook and Russell, 2006)], $1.25 \mu 110 \mathrm{X}$ dNTPs (2.5 mM dATP, $2.5 \mathrm{mM} \mathrm{dCTP,} 2.5 \mathrm{mM}$ dGTP, 2.5 mM TTP; GE Healthcare Life Sciences, Inc.), $0.5 \mu 15 \mathrm{U} / \mu 1$ Taq DNA polymerase (New England Biolabs, Inc.), $5 \mu 15 \mathrm{M}$ betaine, $0.625 \mu 1$ 100\% dimethyl sulfoxide, and $1.25 \mu 110$ X Taq DNA polymerase buffer; 40 cycles of $30 \mathrm{~s}$ at $95^{\circ} \mathrm{C}, 30 \mathrm{~s}$ at $53^{\circ} \mathrm{C}$, and $30 \mathrm{~s}$ at $72^{\circ} \mathrm{C}$. Reactions were stopped by addition of $12.5 \mu 11 \mathrm{X}$ TBE, $8 \mathrm{M}$ urea, $0.025 \%$ xylene cyanol, and $0.025 \%$ bromophenol blue; radiolabeled products were separated by electrophoresis on $8 \%, 8 \mathrm{M}$ urea, $1 \mathrm{X}$ TBE polyacrylamide gels (UreaGel System; National Diagnostics, Inc.) and visualized by storage-phosphor imaging (Typhoon 9400 variable-mode imager; GE Healthcare Life Sciences, Inc.). Positions of RNAP-DNA crosslinking were determined by comparison to products of a DNA-nucleotide sequencing reaction generated using oligo N25T (when mapping trailing-edge crosslinks) or N25B (when mapping leading edge crosslinks) and a linear DNA template containing sequences from positions -72 to +71 of N25 (Thermo Sequenase Cycle Sequencing Kit; Affymetrix Inc.).

\section{DNA templates for single-molecule DNA nanomanipulation}

Plasmid pUC18-T20-N25-WT, which was used for experiments with the N25 promoter, was prepared as follows: The pUC18-T20 backbone was amplified by performing PCR using $1 \mathrm{ng}$ of pUC18-T20 (Yu et al., 2017) in a $50 \mu 1$ reaction containing 1 X Phusion HF Master Mix, $0.8 \mu \mathrm{M}$ oligo JW151 and $0.8 \mu \mathrm{M}$ oligo JW152, and amplicons were digested with 30 units of DpnI (New England Biolabs, Inc.) for $30 \mathrm{~min}$ at $37^{\circ} \mathrm{C}$. The N25 promoter was amplified by PCR using $1 \mathrm{ng} \mathrm{JW} 173$ in $50 \mu 1$ reactions containing $1 \mathrm{X}$ Phusion HF Master Mix, $0.8 \mu \mathrm{M}$ oligo JW179, and $0.8 \mu \mathrm{M}$ oligo JW180, and the amplicon was isolated using a PCR purification kit (Qiagen, Inc.). Gibson assembly was performed by combining 100 ng of DpnI-digested pUC18-T20 amplicon with 25 ng of the N25 promoter amplicon in 5 $\mu 12$ X Gibson Assembly Master Mix (New England Biolabs, Inc.) in $10 \mu 1$ reactions and incubating 15 min at $50^{\circ} \mathrm{C}$. The ligation mixture was diluted 2 -fold with ultrapure water and was used to transform NEB 5-alpha electrocompetent cells (New England Biolabs, Inc.). Transformants were plated on LB agar plates 
containing $100 \mu \mathrm{g} / \mathrm{ml}$ carbenicillin, and recombinant plasmid DNA was isolated from individual transformants.

Plasmids pUC18-T20-N25[ $\left.\mathrm{G}_{+1} \mathrm{G}_{+2} \mathrm{G}_{+3}\right]$ and pUC18-T20-N25[C $\left.\mathrm{C}_{+1} \mathrm{C}_{+2} \mathrm{C}_{+3}\right]$, which were used for experiments with the $\mathrm{N} 25\left[\mathrm{G}_{+1} \mathrm{G}_{+2} \mathrm{G}_{+3}\right]$ promoter and the $\mathrm{N} 25\left[\mathrm{C}_{+1} \mathrm{C}_{+2} \mathrm{C}_{+3}\right]$ promoter, were prepared in the same manner, but using JW169 and JW170, respectively, in place of JW173

$2.0 \mathrm{~kb}$ DNA fragments carrying single centrally located $\mathrm{N} 25, \mathrm{~N} 25\left[\mathrm{G}_{+1} \mathrm{G}_{+2} \mathrm{G}_{+3}\right]$, or N25

$\left[\mathrm{C}_{+1} \mathrm{C}_{+2} \mathrm{C}_{+3}\right]$ promoters were prepared by digesting plasmid pUC18-T20C2-N25-WT, plasmid

pUC18-T20C2-N25 $\left[\mathrm{G}_{+1} \mathrm{G}_{+2} \mathrm{G}_{+3}\right]$, or plasmid pUC18-T20C2-N25 $\left[\mathrm{C}_{+1} \mathrm{C}_{+2} \mathrm{C}_{+3}\right]$ with XbaI and SbfI-HF

(New England Biolabs, Inc.), followed by agarose gel electrophoresis and isolation of DNA from the gel using a gel extraction kit (Qiagen, Inc.).

Starting from the above $2.0 \mathrm{~kb}$ pUC18 DNA segments, constructs for single-molecule DNA nanomanipulation were prepared via ligation, at the $\mathrm{XbaI}$ end, to a $1.0 \mathrm{~kb}$ DNA fragment carrying multiple biotin residues on both strands [generated by PCR amplification of plasmid pARTaqRPOC-lacCONS) (Revyakin et al., 2003) with primers RPOC3140 and XbaRPOC4050 (Table S2) as described (Revyakin et al., 2003; Revyakin et al., 2004, 2005; Revyakin et al., 2006), followed by digestion with XbaI (New England Biolabs, Inc.)] and, then, at the SbfI end, to a $1.0 \mathrm{~kb}$ DNA fragment carrying multiple digoxigenin residues on both strands [generated by PCR amplification of plasmid pARTaqRPOC-lacCONS (Yu et al., 2017) with primers RPOC820 and SbfRPOC50 (Table S2) as described (Revyakin et al., 2003; Revyakin et al., 2004, 2005; Revyakin et al., 2006), followed by digestion with SbfI-HF (New England Biolabs, Inc.)]. The resulting constructs were linked to streptavidin-coated magnetic beads ( $1 \mu \mathrm{m}$ diameter, MyOne Streptavidin C1; Life Technologies, Inc.), immobilized on a glass surface coated with anti-digoxigenin (prepared as in (Lionnet et al., 2012)) and calibrated as described (Revyakin et al., 2003; Revyakin et al., 2004, 2005; Revyakin et al., 2006).

Measurement of RNAP-dependent DNA unwinding by single-molecule DNA nanomanipulation: data collection 
Experiments were performed essentially as described (Revyakin et al., 2003; Revyakin et al., 2004, 2005; Revyakin et al., 2006). We tested a $2.0 \mathrm{~kb}$, mechanically extended, torsionally constrained, DNA molecule carrying N25 WT, N25 $\left[\mathrm{C}_{+1} \mathrm{C}_{+2} \mathrm{C}_{+3}\right]$, or N25 $\left[\mathrm{G}_{+1} \mathrm{G}_{+2} \mathrm{G}_{+3}\right]$ (superhelical density $=0.021$ for experiments with positively supercoiled DNA; superhelical density $=-0.021$ for experiments with negatively supercoiled DNA; extension force $=0.3 \mathrm{pN})$. E. coli $\mathrm{RNAP} \sigma^{70}$ holoenzyme was used at $10 \mathrm{nM}$ in experiments with positively supercoiled DNA and at $0.5 \mathrm{nM}$ for experiments with negatively supercoiled DNA. The assay buffer contained $25 \mathrm{mM}$ Na-HEPES (pH 7.9), $75 \mathrm{mM} \mathrm{NaCl}, 10 \mathrm{mM} \mathrm{MgCl}$, $1 \mathrm{mM}$ dithiothreitol, $0.1 \mathrm{mg} / \mathrm{mL}$ BSA, and 0.1\% Tween-20. NTPs (ATP, GTP, UTP, and CTP; GE Healthcare Life Sciences, Inc.) were used at $0.5 \mathrm{mM}$. Experiments were performed at $30^{\circ} \mathrm{C}$. For each promoter, all data were collected on a single DNA molecule. For experiments with negatively supercoiled DNA, in which $t_{\text {unwound }}>1$ h (Revyakin et al., 2003; Revyakin et al., 2004, 2005; Revyakin et al., 2006), the unwound DNA was mechanically disrupted after 1 min as described (Revyakin et al., 2003; Revyakin et al., 2004, 2005; Revyakin et al., 2006), by rotating the magnets 8 turns counterclockwise to introduce positive superhelical turns (superhelical density $=0.021$ ), waiting for $1 \mathrm{~min}$, and rotating magnets 8 turns clockwise to re-introduce negative superhelical turns (superhelical density $=-0.021$ ) and reform unwound complexes.

Measurement of RNAP-dependent DNA unwinding by single-molecule DNA nanomanipulation: data reduction

Raw time traces were analyzed to give DNA extension $(l)$ as described (Revyakin et al., 2003; Revyakin et al., 2004, 2005; Revyakin et al., 2006). Changes in $l$ resulting from DNA unwinding $\left(\Delta l_{u}\right)$ were calculated as $\Delta l_{u}=\left(\Delta l_{\text {obs,neg }}+\Delta l_{\text {obs,pos }}\right) / 2$, where $\Delta l_{\text {obs,pos }}$ is the observed change in $l$ in assays with positively supercoiled DNA, and $\Delta l_{o b s, n e g}$ is the observed change in $l$ with negatively supercoiled DNA. Extents of DNA unwinding (in base pairs) were calculated as $\left(\Delta l_{u} / \delta\right) 10.4$, where $\delta(55 \mathrm{~nm})$ is the change 
in $l$ per turn at the superhelical densities of this work $(+/-0.021)$, and 10.4 is the mean number of base pairs in each turn of B-DNA (Wang, 1979).

\section{Statistical analysis}

Data for single-molecule DNA nanomanipulation are means \pm SEM of at least 50 technical replicates on a single, positively supercoiled DNA molecule, or at least 40 technical replicates on a single, negatively supercoiled DNA molecule. 
Table S1. Data collection and refinement statistics. ${ }^{a}$

\begin{tabular}{|c|c|c|c|}
\hline Complex & RPitc,5 & RPrtc, $5\left[\mathbf{G}_{+1} \mathbf{G}_{+2} \mathbf{G}_{+3}\right]$ & RPrtc, $4\left[\mathbf{C}_{+1} \mathbf{C}_{+2} \mathbf{C}_{+3}\right]$ \\
\hline PDB code & $7 \mathrm{MLB}$ & $7 \mathrm{MLI}$ & $7 \mathrm{MLJ}$ \\
\hline Beamline & APS19-ID & SSRL-9-2 & SSRL-9-2 \\
\hline Resolution range & $\begin{array}{l}50.00-3.60 \\
(3.66-3.60)\end{array}$ & $\begin{array}{l}50.00-3.60 \\
(3.66-3.60)\end{array}$ & $\begin{array}{l}50.00-3.75 \\
(3.81-3.75)\end{array}$ \\
\hline Space group & C 121 & C 121 & C 121 \\
\hline Unit cell & $\begin{array}{r}186.17104 .27 \\
299.029097 .9590\end{array}$ & $\begin{array}{r}187.08103 .88298 .74 \\
9097.9590\end{array}$ & $\begin{array}{r}186.31104 .66298 .41 \\
9098.1290\end{array}$ \\
\hline Unique reflections & $66110(3055)$ & $64844(3172)$ & $57607(2910)$ \\
\hline Multiplicity & $4.0(3.3)$ & $4.2(3.9)$ & $4.2(4.2)$ \\
\hline Completeness (\%) & $98.5(92.3)$ & $96.84(91.38)$ & $96.97(93.60)$ \\
\hline Mean I/sigma(I) & 10.7 & 10.8 & 14.5 \\
\hline Wilson B-factor & 116.36 & 107.75 & 114.24 \\
\hline R-merge & $0.116(0.845)$ & $0.151(1.36)$ & $0.103(1.031)$ \\
\hline CC1/2 & $(0.624)$ & $(0.912)$ & $(0.837)$ \\
\hline $\begin{array}{l}\text { Reflections used in } \\
\text { refinement }\end{array}$ & $65151(6097)$ & 64469 (5989) & $57263(5466)$ \\
\hline R-work/R-free & $0.2330 / 0.2697$ & $0.2432 / 0.2918$ & $0.2654 / 0.2833$ \\
\hline Number of non-H atoms & 28400 & 28502 & 28489 \\
\hline RMS(bonds) & 0.002 & 0.002 & 0.002 \\
\hline RMS(angles) & 0.53 & 0.54 & 0.52 \\
\hline Ramachandran favored (\%) & 98.44 & 98.30 & 97.84 \\
\hline Ramachandran outliers (\%) & 0.09 & 0.14 & 0.12 \\
\hline Rotamer outliers (\%) & 6.37 & 6.37 & 5.63 \\
\hline Clashscore & 6.16 & 6.41 & 6.22 \\
\hline
\end{tabular}

a Statistics for the highest-resolution shell are shown in parentheses. 
Table S2. Oligonucleotides

\begin{tabular}{|c|c|c|}
\hline Name & Sequence (5' to $\left.3^{\prime}\right)$ & Description \\
\hline N25T & $\begin{array}{l}\text { GAGAGAGGTACCTCGA } \\
\text { GG }\end{array}$ & $\begin{array}{l}\text { PCR primer for production of DNA templates } \\
\text { containing N25 promoter derivatives and for } \\
\text { primer-extension mapping of leading-edge } \\
\text { crosslinks }\end{array}$ \\
\hline N25B & $\begin{array}{l}\text { CTGTTCGATTGGGATG } \\
\text { GCTATTCGG }\end{array}$ & $\begin{array}{l}\text { PCR primer for production of DNA templates } \\
\text { containing N25 promoter derivatives and for } \\
\text { primer-extension mapping of trailing-edge } \\
\text { crosslinks }\end{array}$ \\
\hline JW151 & $\begin{array}{l}\text { GGTACCTCTGCTTCTCC } \\
\text { TCGGGGATCACG }\end{array}$ & $\begin{array}{l}\text { PCR primer for amplification of pUC18-T20 } \\
\text { backbone }\end{array}$ \\
\hline JW152 & $\begin{array}{l}\text { GGTACCTGGAGGAAGC } \\
\text { CGACCGGAAGC }\end{array}$ & $\begin{array}{l}\text { PCR primer for amplification of pUC18-T20 } \\
\text { backbone }\end{array}$ \\
\hline JW169 & $\begin{array}{l}\text { GAGAGAGGTACCTCGA } \\
\text { GGGAAATCATAAAAAAT } \\
\text { TTATTTGCTTTCAGGAA } \\
\text { AATTTTTCTGTATAATAG } \\
\text { ATTCCCCATTTGAGAGA } \\
\text { GGAGTTTAAATATGGCT } \\
\text { GGTTCTCGCGAGAATT } \\
\text { CCGAATAGCCATCCCA } \\
\text { ATCGAACAG }\end{array}$ & $\begin{array}{l}\mathrm{N} 25\left[\mathrm{G}_{+1} \mathrm{G}_{+2} \mathrm{G}+3\right] \text { template-strand oligonucleotide, } \\
\text { used in } \mathrm{PCR} \text { with primers JW179 and JW180 to } \\
\text { produce } \mathrm{N} 25\left[\mathrm{G}_{+1} \mathrm{G}_{+2} \mathrm{G}_{+3}\right] \text { DNA fragment to insert } \\
\text { into pUC18-T20 for single molecule DNA } \\
\text { nanomanipulation assays and used in PCR with } \\
\text { primers N25T and N25B to produce N25 } \\
{\left[\mathrm{G}_{+1} \mathrm{G}_{+2} \mathrm{G}_{+3}\right] \text { DNA fragment for in vitro transcription }} \\
\text { and crosslinking assays. }\end{array}$ \\
\hline JW170 & $\begin{array}{l}\text { GAGAGAGGTACCTCGA } \\
\text { GGGAAATCATAAAAAAT } \\
\text { TTATTTGCTTTCAGGAA } \\
\text { AATTTTTCTGTATAATAG } \\
\text { ATTCGGGATTTGAGAGA } \\
\text { GGAGTTTAAATATGGCT } \\
\text { GGTTCTCGCGAGAATT } \\
\text { CCGAATAGCCATCCCA } \\
\text { ATCGAACAG }\end{array}$ & $\begin{array}{l}\mathrm{N} 25\left[\mathrm{C}_{+1} \mathrm{C}_{+2} \mathrm{C}_{+3}\right] \text { template-strand oligonucleotide, } \\
\text { used in PCR with primers JW179 and JW180 to } \\
\text { produce DNA fragment to insert into pUC18-T20 } \\
\text { for single molecule DNA nanomanipulation assays } \\
\text { and used in PCR with primers N25T and N25B to } \\
\text { produce } \mathrm{N} 25\left[\mathrm{C}+\mathrm{C}_{+2} \mathrm{C}+3\right] \text { DNA fragment for in vitro } \\
\text { transcription and crosslinking assays. }\end{array}$ \\
\hline JW173 & $\begin{array}{l}\text { GAGAGAGGTACCTCGA } \\
\text { GGGAAATCATAAAAAAT } \\
\text { TTATTTGCTTTCAGGAA } \\
\text { AATTTTTCTGTATAATAG } \\
\text { ATTCATAATTTGAGAGA } \\
\text { GGAGTTTAAATATGGCT } \\
\text { GGTTCTCGCGAGAATT } \\
\text { CCGAATAGCCATCCCA } \\
\text { ATCGAACAG }\end{array}$ & $\begin{array}{l}\text { N25 WT template-strand oligonucleotide used in } \\
\text { PCR with primers JW179 and JW180 to produce } \\
\text { DNA fragment to insert into pUC18-T20 for single } \\
\text { molecule DNA nanomanipulation assays and used } \\
\text { in PCR with primers N25T and N25B to produce } \\
\text { N25 WT DNA fragment for in vitro transcription } \\
\text { and crosslinking assays. }\end{array}$ \\
\hline JW179 & $\begin{array}{l}\text { CGAGGAGAAGCAGAGG } \\
\text { TACCCTGTTCGATTGGG } \\
\text { ATGGCTA }\end{array}$ & $\begin{array}{l}\mathrm{PCR} \text { primer for amplification of } \mathrm{N} 25 \text { and } \mathrm{N} 25 \\
\text { derivative DNA fragments to insert into pUC18-T20 }\end{array}$ \\
\hline JW180 & $\begin{array}{l}\text { GTCGGCTTCCTCCAGG } \\
\text { TACCGAGAGAGGTACC } \\
\text { TCGAGGGA }\end{array}$ & $\begin{array}{l}\text { PCR primer for amplification of } \mathrm{N} 25 \text { and } \mathrm{N} 25 \\
\text { derivative DNA fragments to insert into pUC18-T20 }\end{array}$ \\
\hline XbaRPOC4050 & $\begin{array}{l}\text { GAGAGTTCTAGAGACC } \\
\text { TTCTGGATCTCGTCCAC } \\
\text { CAGG }\end{array}$ & $\begin{array}{l}\text { PCR primer for production of } 1 \mathrm{~kb} \text { biotin-labelled } \\
\text { DNA fragments for nanomanipulation experiments }\end{array}$ \\
\hline RPOC3140 & $\begin{array}{l}\text { CTGATGCAAAAGCCCT } \\
\text { CGGG }\end{array}$ & $\begin{array}{l}\text { PCR primer for production of } 1 \mathrm{~kb} \text { biotin-labelled } \\
\text { DNA fragments for nanomanipulation experiments }\end{array}$ \\
\hline SbfRPOC50 & $\begin{array}{l}\text { GAGAGACCTGCAGGGA } \\
\text { GAAGATCCGCTCCTGG }\end{array}$ & $\begin{array}{l}\text { PCR primer for production of } 1 \mathrm{~kb} \\
\text { digoxigenin-labelled DNA fragments for }\end{array}$ \\
\hline
\end{tabular}




\begin{tabular}{|c|c|c|}
\hline & AGCTACG & nanomanipulation experiments \\
\hline RPOC820 & $\begin{array}{l}\text { TCCTGGCGCAGGTAGA } \\
\text { TGAG }\end{array}$ & $\begin{array}{l}\text { PCR primer for production of } 1 \mathrm{~kb} \\
\text { digoxigenin-labelled DNA fragments for } \\
\text { nanomanipulation experiments }\end{array}$ \\
\hline RPitc,5-T & $\begin{array}{l}\text { CCTGCATCCCTGAGTG } \\
\text { GAGGG }\end{array}$ & $\begin{array}{l}\text { template-strand oligonucleotide used in } \\
\text { nucleic-acid scaffold for RPitc, } 5 \text { crystallization }\end{array}$ \\
\hline RPitc,5-NT & $\begin{array}{l}\text { TATAATGGGAGCTGTCA } \\
\text { GGGATGCAGG }\end{array}$ & $\begin{array}{l}\text { nontemplate-strand oligonucleotide used in } \\
\text { nucleic-acid scaffold for RPitc, } 5 \text { crystallization }\end{array}$ \\
\hline $\begin{array}{l}\text { RPrtc,5 } \\
{\left[\mathrm{G}_{+1} \mathrm{G}_{+2} \mathrm{G}_{+3}\right]-\mathrm{T}}\end{array}$ & $\begin{array}{l}\text { CCTGCATCCGTAGGGC } \\
\text { GAGG }\end{array}$ & $\begin{array}{l}\text { template-strand oligonucleotide used in } \\
\text { nucleic-acid scaffold for RPrtc, } 5\left[\mathrm{G}_{+1} \mathrm{G}_{+2} \mathrm{G}_{+3}\right] \\
\text { crystallization }\end{array}$ \\
\hline $\begin{array}{l}\text { RPrtc,5 } \\
{\left[G_{+1} G_{+2} G_{+3}\right]-N T}\end{array}$ & $\begin{array}{l}\text { TATAATGGGAGCTGCTA } \\
\text { CGGATGCAGG }\end{array}$ & $\begin{array}{l}\text { nontemplate-strand oligonucleotide used in } \\
\text { nucleic-acid scaffold for RPrtc, } 5\left[\mathrm{G}_{+1} \mathrm{G}_{+2} \mathrm{G}_{+3}\right] \\
\text { crystallization }\end{array}$ \\
\hline $\begin{array}{l}\text { RPrtc, } 4 \\
{\left[\mathrm{C}_{+1} \mathrm{C}_{+2} \mathrm{C}+3\right]-\mathrm{T}}\end{array}$ & $\begin{array}{l}\text { CCTGCATCCGTGCCCT } \\
\text { GAGG }\end{array}$ & $\begin{array}{l}\text { template-strand oligonucleotide used in } \\
\text { nucleic-acid scaffold for RPrtc, } 4\left[\mathrm{C}_{+1} \mathrm{C}_{+2} \mathrm{C}_{+3}\right] \\
\text { crystallization }\end{array}$ \\
\hline $\begin{array}{l}\text { RPrtc, } 4 \\
{\left[\mathrm{C}_{+1} \mathrm{C}_{+2} \mathrm{C}_{+3}\right]-\mathrm{NT}}\end{array}$ & $\begin{array}{l}\text { TATAATGGGAGCTGGCAC } \\
\text { GGATGCAGG }\end{array}$ & $\begin{array}{l}\text { nontemplate-strand oligonucleotide, used in nucleic-acid } \\
\text { scaffold for RPrtc, } 4\left[\mathrm{C}_{+1} \mathrm{C}_{+2} \mathrm{C}_{+3}\right] \text { crystallization }\end{array}$ \\
\hline $\begin{array}{l}\text { RPrtc, } 11 \\
{\left[\mathrm{C}_{+1} \mathrm{C}_{+2} \mathrm{C}_{+3}\right]-\mathrm{T}}\end{array}$ & $\begin{array}{l}\text { CCTGCATCCGTGCCCTGA } \\
\text { GGGTAATAAGCACAC }\end{array}$ & $\begin{array}{l}\text { template-strand oligonucleotide used in nucleic-acid } \\
\text { scaffold for RPrtc, } \geq 11\left[\mathrm{C}_{+1} \mathrm{C}_{+2} \mathrm{C}_{+3}\right] \text { cryo-EM }\end{array}$ \\
\hline $\begin{array}{l}\text { RPrtc, } 11 \\
{\left[\mathrm{C}_{+1} \mathrm{C}_{+2} \mathrm{C}_{+3}\right]-\mathrm{NT}}\end{array}$ & $\begin{array}{l}\text { GTGTGCTATAATGGGAGC } \\
\text { TGGCACGGATGCAGG }\end{array}$ & $\begin{array}{l}\text { nontemplate-strand oligonucleotide, used in nucleic-acid } \\
\text { scaffold for RPrtc, } \geq 11\left[\mathrm{C}_{+1} \mathrm{C}_{+2} \mathrm{C}_{+3}\right] \text { cryo-EM }\end{array}$ \\
\hline
\end{tabular}




\section{Supplemental Figure Legends}

\section{Figure S1. Standard transcription initiation and reiterative transcription initiation.}

(A) In vitro transcription experiments with nucleic-acid scaffolds used in crystal structure determination of Figures 1-2 ("partial bubble") and cryo-EM structure determination of Figures 3-4 ("full bubble"). Left, nucleic-acid scaffolds (promoter -35 and -10 elements, blue; promoter discriminator elements, light blue; template-strand homopolymeric sequences, red; non-complementary sequences, raised and lowered nucleotides; transcription start sites, +1). Right, in vitro transcription products with T. thermophilus RNAP $\sigma^{\text {A }}$ holoenzyme $(T t h)$ and E. coli RNAP $\sigma^{70}$ holoenzyme $(E c o)$ for partial-bubble scaffold 1 (template-strand non-homopolymeric transcription-start-site sequence $\mathrm{T}_{+1} \mathrm{G}_{+1} \mathrm{~A}_{+1}$; transcription with ATP and UTP; standard transcription initiation), partial-bubble scaffold 2 (template-strand homopolymeric sequence $\mathrm{G}_{+1} \mathrm{G}_{+2} \mathrm{G}_{+3}$; transcription with CTP; reiterative transcription initiation), partial-bubble scaffold 3 (template-strand homopolymeric sequence $\mathrm{C}_{+1} \mathrm{C}_{+2} \mathrm{C}_{+3}$; transcription with GTP; reiterative transcription initiation), and full-bubble scaffold 4 (template-strand homopolymeric sequence $\mathrm{C}_{+1} \mathrm{C}_{+2} \mathrm{C}_{+3}$; transcription with GTP; reiterative transcription initiation).

(B) In vitro transcription experiments with bacteriophage T5 N25 promoter derivatives used in photocrosslinking and single-molecule DNA-nanomanipulation experiments of Figures 5-6. Left, promoter sequences (colors as in panel A). Right, in vitro transcription products with and E. coli RNAP $\sigma^{70}$ holoenzyme $(E c o)$ for bacteriophage N25 WT (transcription with ATP and UTP; standard transcription initiation), $\mathrm{N} 25\left[\mathrm{G}_{+1} \mathrm{G}_{+2} \mathrm{G}_{+3}\right]$ (template-strand homopolymeric sequence $\mathrm{G}_{+1} \mathrm{G}_{+2} \mathrm{G}_{+3}$; transcription with CTP; reiterative transcription initiation), and $\mathrm{N} 25\left[\mathrm{C}_{+1} \mathrm{C}_{+2} \mathrm{C}_{+3}\right]($ template-strand homopolymeric sequence $\mathrm{C}_{+1} \mathrm{C}_{+2} \mathrm{C}_{+3}$; transcription with GTP; reiterative transcription initiation). RNA products 2-10 nt in length are products of standard transcription initiation or reiterative transcription initiation; RNA products $>10 \mathrm{nt}$ in length are products of reiterative transcription initiation. 
Figure S2. Cryo-EM structure determination: RPrtc, $\geq 11\left[\mathrm{C}_{+1} \mathrm{C}_{+2} \mathrm{C}_{+3}\right]$

(A) Data processing scheme.

(B) Representative electron micrograph (left; $50 \mathrm{~nm}$ scale bar) and representative class averages (right, 20 nm scale bar).

(C) Orientational distribution.

(D) Fourier-shell-correlation (FSC) plot.

(E) EM density maps colored by local resolution. Left, overall structure. Center, overall structure, omitting $\beta^{\prime}$ non-conserved region. Right, DNA and RNA in structure. View orientations as in Figures 3A-B, D.

Figure S3. RNAP and $\sigma$ residues that make protein-RNA interactions in alternative RNA pathway and alternative RNA exit: sequence-conservation patterns of

Locations of residues that make protein-RNA interactions with rN6-rN11 in the structure of RPrtc, $\geq 11$ $\left[\mathrm{C}_{+1} \mathrm{C}_{+2} \mathrm{C}_{+3}\right]$ in the sequences of RNAP $\beta$ subunit (left) and $\sigma$ (right). Sequence alignments for $\beta$ and $\sigma^{70} / \sigma^{\mathrm{A}}$ for Gram-negative, Gram-positive, and Thermus-Deinococcus-clade bacterial species showing locations of RNAP residues that contact protein-RNA interactions with rN6-rN11 (black rectangles; numbered as in T. thermophilus and, in parentheses, as in E. coli; identities from Figure 4C), and locations of RNAP and $\sigma$ structural elements and conserved regions (black bars; Feklistov et al., 2014; Lane and Darst, 2010). Species are as follows: E. coli (ECOLI), Salmonella typhimurium (SALTY), Klebsiella pneumoniae (KLEP7), Enterobacter cloacae (ENTCC), Vibrio cholerae (VIBCH), Haemophilus influenzae (HAEIN), Neisseria gonorrhoeae (NEIG1), Stenotrophomonas maltophilia (STPMP), Moraxella catarrhalis (MORCA), Acinetobacter baumannii (ACIBC), Pseudomonas aeruginosa (PSEAE), Staphylococcus aureus (STAAU), Staphylococcus epidermidis (STAEQ), Enterococcus faecalis (ENTFA), Streptococcus pyogenes (STRP1), Streptococcus pneumoniae (STRP2), Clostridium difficile (CDIFF), Mycobacterium tuberculosis (MYCTU), Mycobacterium avium (MYCA1), 
Mycobacterium abscessus (MYCA9), Thermus aquaticus (THEAQ), and Thermus thermophilus (TTHER), and Deinococcus radiodurans (DEIRA).

\section{Figure S4. Hypothesized mechanisms for synthesis of long RNA products ( $>10 \mathrm{nt}$ ) through} reiterative transcription initiation.

The part of the $\sigma$ finger that occupies the RNAP hybrid binding site is colored dark yellow; the part of the $\sigma$ region-3/region-4 linker that occupies the RNAP RNA-exit channel is colored brown. Non-templated, reiterative-transcription-dependent RNA nucleotides are colored magenta; templated, standard-transcription-dependent RNA nucleotides are colored orange. Other symbols and colors are as in Figures 5 and 7.

(Left) Hypothesized mechanism for synthesis of long RNA products comprising only non-templated, reiterative-transcription-dependent nucleotides ("non-productive" reiterative transcription initiation by RPrtc, without displacement of the $\sigma$ finger, displacement of the $\sigma$ region-3/region-4 linker, and promoter escape).

(Right) Hypothesized mechanism for synthesis of long RNA products comprising non-templated, reiterative-transcription-dependent nucleotides at their 5' ends followed by templated, standard-transcription-dependent nucleotides ("productive" reiterative transcription initiation, entailing switching from reiterative transcription initiation by RPitc to standard transcription initiation by RPrtc $\rightarrow$ itc, resulting in displacement of the $\sigma$ finger, displacement of the $\sigma$ region-3/region- 4 linker, promoter escape, optional $\sigma$ release, and transcription elongation using an RNAP-stepping mechanism). 


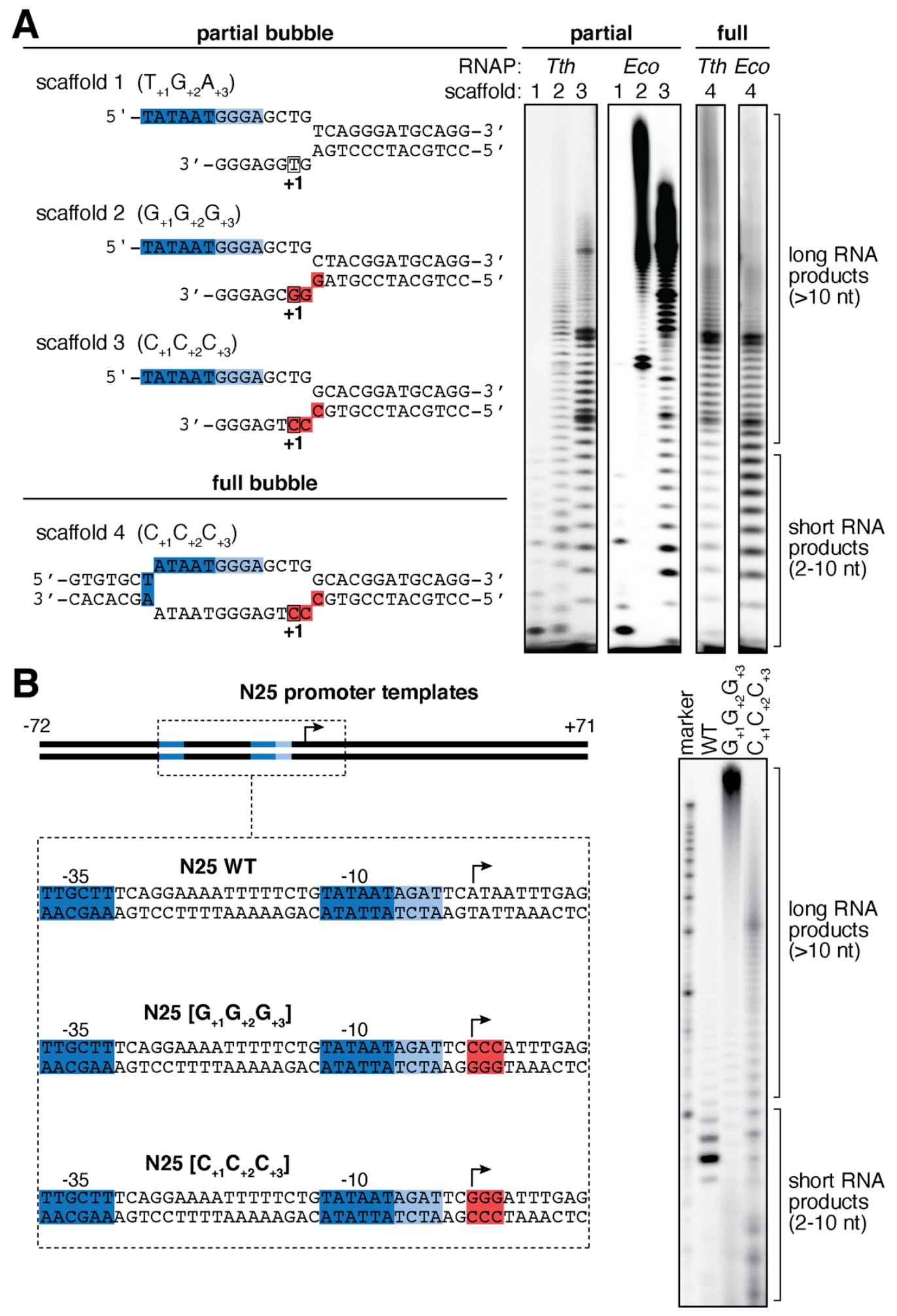

\section{Figure S1}




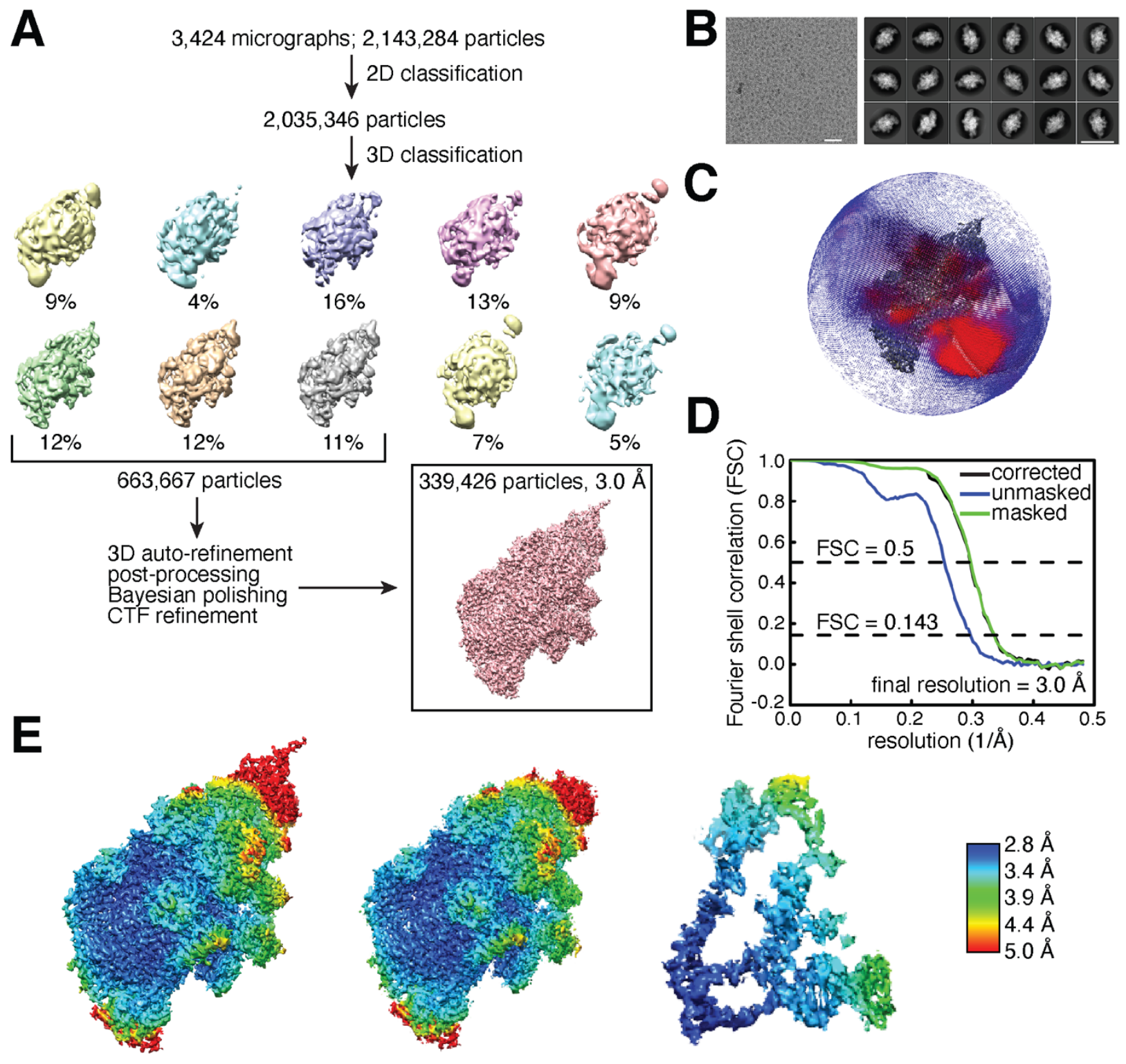

Figure S2 
bioRxiv preprint doi: https://doi.org/10.1101/2021.05.08.443277; this version posted August 14, 2021. The copyright holder for this preprint (which was not certified by peer review) is the author/funder. All rights reserved. No reuse allowed without permission.

residues in $\beta$

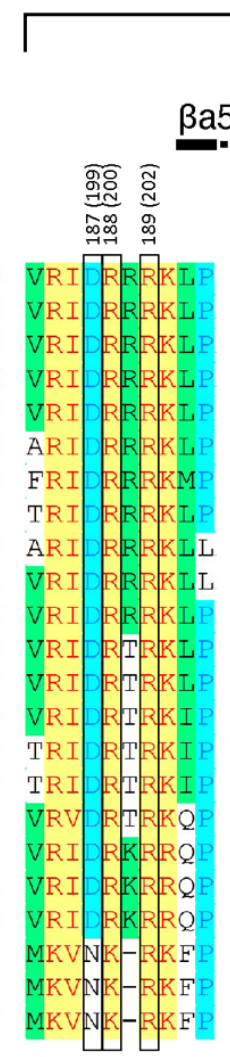

RPOB_ECOLI 196 RPOB SALTY 196 RPOB-KLEP7 196 RPOB ENTCC 196 RPOB_VIBCH 196 RPOB HAEIN 196 RPOB NEIG1 200 RPOB STPMP 201 RPOB ${ }^{-}$MORCA 199 RPOB ACIBC 198 RPOB PSEAE 200 RPOB STAAU 182 $\mathrm{RPOB}^{-} \mathrm{STAEQ} 182$ RPOB ENTFA 185 RPOB STRP1 182 RPOB STRP2 182 RPOB CDIFF 181 RPOB MYCTU 224 RPOB MYCA1 224 RPOB MYCA9 218 RPOB THEAQ 184 RPOB TTHER 184 RPOB_DEIRA 200
FL2
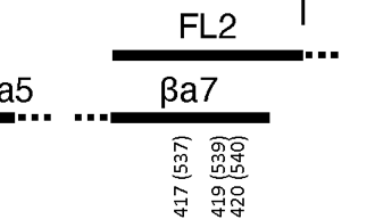

534 GPGGLTRERA

534 GPGGLTRERA

534 GPGGLTRERA

534 GPGGLTRERA

534 GPGGLTRERA

534 GPGGLTRERA

561 GPGGLTRERA

562 GPGGLTRERA

544 GPGGLTRERA

543 GPGGLTRERA

539 GPGGLTRERA

489 GPGGLTRERA

489 GPGGLTRERA

497 GPGGLTRDRA

494 GPGGLTRDRA

494 GPGGLTRDRA

510 GPGGLSRERA

459 GPGGLSRERA

459 GPGGLSRERA

455 GPGGLTRDRA

414 GPGGLTRERA

414 GPGGLTRERA

443 GPGGLTRERA residues in $\sigma$

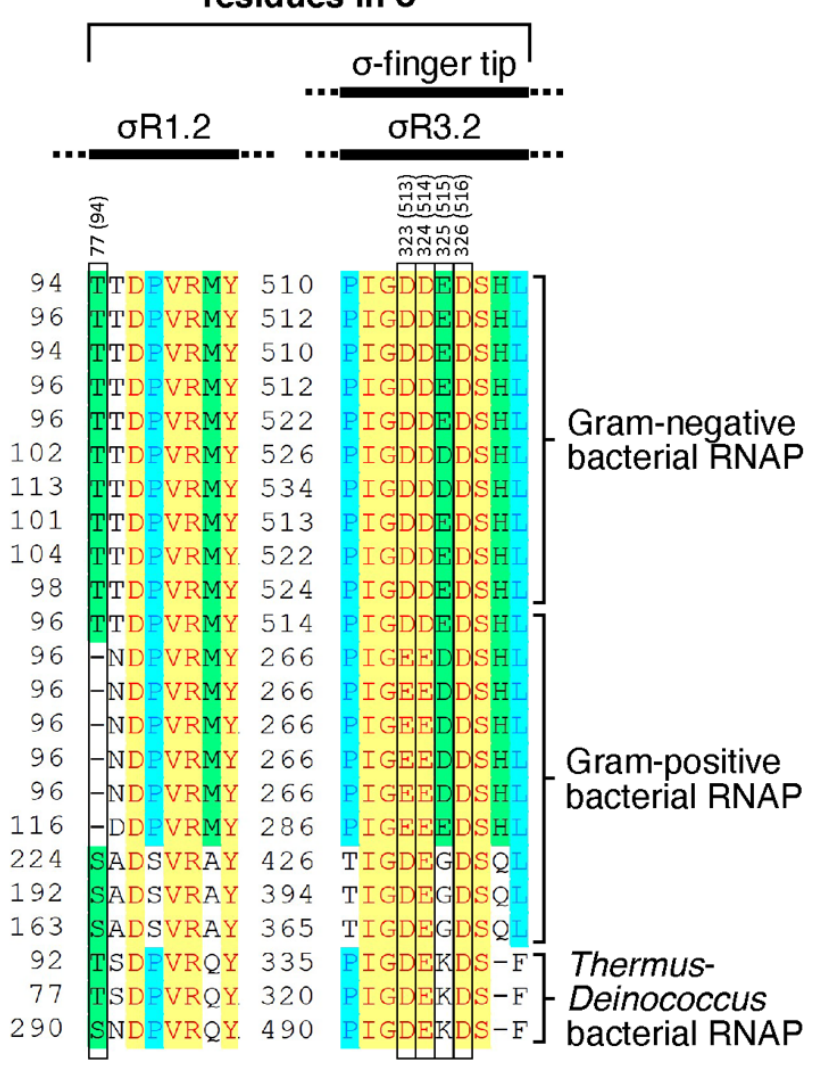

Figure S3 




\section{Figure S4}

